\title{
Novel Experimental and 3D Multiphysics Computational Framework for Analyzing Deformation and Failure of Composite Laminates Subjected to Water Blasts
}

\author{
Siddharth Avachat and Min Zhou ${ }^{1}$ \\ The George W. Woodruff School of Mechanical Engineering, \\ School of Materials Science and Engineering \\ Georgia Institute of Technology \\ Atlanta, GA 30332-0405, USA
}

The load-carrying capacity of composite structures under water-based impulsive loads is studied in relation to different materials and loading conditions. The analysis focuses on the role of fiber orientation, fiber stiffness and angle of structure obliquity relative to load direction on the deformation and failure in monolithic carbon-fiber and glass-fiber/epoxy composite plates of similar mass and thickness. Structures are subjected to impulsive loads of different intensities generated using the Underwater Shock Loading Simulator (USLS), a novel projectile-impactbased impulsive loading facility. In-situ high-speed digital imaging is used to study the deformation and failure, focusing on the effects of load intensity, failure modes and material heterogeneity. The experiments are combined with fully dynamic 3D Coupled Eulerian Lagrangian (CEL) finite element simulations accounting for the effects of fluid-structure interactions (FSI) and in-ply and inter-ply cracking and failure. It is found that the carbon-fiber laminates provide higher blast resistance, but transmit a greater fraction of the incident impulse to the supports than the glass-fiber laminates. Damage through in-ply and inter-ply cracking in the carbon-fiber laminates is $\sim 25 \%$ of that in the glass-fiber laminates. Higher angles of load

\footnotetext{
${ }^{1}$ To whom correspondence should be addressed, Tel: 404894 3294, Fax: 404894 0186, Email: min.zhou@ gatech.edu
} 
obliquity trigger localized deformation at multiple locations, leading to more extensive in-ply damage and progressively shear-dominated rupture.

\section{Introduction}

The response of composite structures to both contact-induced dynamic and water-based impulsive loads is of great importance in the design of failure-resistant marine structures for naval and off-shore industry applications in which composite materials have been increasingly employed. As a consequence, there is an increasing need to understand and quantify the response of composite structures to such high-intensity dynamic and impulsive loads. Chang and coworkers [1-3] have studied the damage behavior of composite laminates under low-velocity impact loading, concluding that in-ply matrix cracking precedes delamination growth and shear and bending crack initiation. The damage behavior of composite laminates is significantly influenced by matrix material, composite layup and geometric aspects such as size, thickness and loading area [4-6]. Minnaar and Zhou [7] used a novel interferometric experimental setup to show that interlaminar crack speeds are significantly higher under shear loading, and that crack speeds are strongly influenced by loading rate in mode II.

Experiments and computations focusing on different core topologies and specimen sizes have been carried out by Espinosa and co-workers [8-10]. Battley [11, 12] developed and used a high-speed servo-hydraulic testing system and concluded that slamming impact on a deformable sandwich panels results in peak and residual pressures different from those for a rigid panels. Shukla and co-workers [13-17] examined the dynamic response of sandwich structures consisting of planar and curved composite structures. A combined experimental and computational analysis of deformation in composite structures subjected to underwater blasts carried out by Avachat and Zhou [18] has revealed that sandwich structures significantly 
outperform monolithic structures at all impulsive levels and environmental conditions including air-backed and water-backed conditions. Schiffer and Tagarielli $[19,20]$ analyzed the onedimensional underwater blast performance of sandwich structures and showed that the impulse imparted to double hulls by underwater explosions can be dramatically reduced by employing the sandwich construction of the outer skin. They discovered a marked improvement in blast resistance in structures comprising a monolithic outer skin and an unsupported inner hull of similar mass in comparison to a stationary inner hull.

Despite the recent interest in the mechanical response of composite structures, especially their behavior under blast loading, there are a number of unresolved issues. Comparative analyses of the blast resistance and dynamic performance of different reinforcements (glassfiber, carbon-fiber), varying anisotropy, different matrix materials (epoxy, polyester, etc.), and varying loading conditions (planar, oblique, cylindrical) are lacking. The objective of the present study is to characterize the damage response of thick composite laminates with different reinforcements and anisotropies under water-based blast loading. The focus is on understanding the deformation and failure mechanisms and quantifying damage as a function of structural attributes, material properties, loading conditions and loading rates. Planar impulses resembling those resulting from underwater explosions are generated using the Underwater Shock Loading Simulator (USLS), a novel experimental setup developed recently. The USLS consists of a projectile-impact-based impulsive loading system, a water chamber, a target holder, and a safety enclosure.

Coupled Eulerian Lagrangian finite element simulations are carried out along with experiments, accounting for the experimental conditions and material properties which are measured independently. The simulations also account for the fluid-structure interaction (FSI) 
effect at the water-composite interface. Failure mechanisms considered include shear cracking and fragmentation, tensile cracking, compressive kinking, and interfacial debonding. The simulations focus on damage initiation and evolution in the early stage of deformation $(\sim 1500$ $\mu \mathrm{s})$ since the load-carrying capacity is most critically reflected then. This combined experimental and numerical approach enables the identification of factors that play important roles in determining the dynamic response of the materials. The analysis uses metrics such as deflection, transmitted impulse and accumulated damage to quantify the blast resistance.

\section{Technical approach}

\section{$\underline{2.1 \text { Composites manufacturing }}$}

Fiber-matrix composites are composed of two distinct phases: (1) reinforcements like glass-fibers or carbon-fibers and (2) matrix materials like epoxy, polyester, etc. The strength and stiffness of the finished composite is determined by the volume fraction and directionality of fibers with respect to external loads. Two types of composite materials are used in this analysis: glass-fiber reinforced epoxy and carbon-fiber reinforced epoxy. The glass-fiber reinforced prepregs are 24-inch wide XF0920/346-AA-675 E-Glass 300 GSM 36\% RW. XF0920 is the resin designation, 346-AA-675 is the identification number of Owens Corning 346 Type 30 roving, 300 GSM denotes the 300 grams per square meter areal mass of the aforementioned glass fiber, 675 denotes the length of the roving in yards per pound, and $36 \% R W$ denotes resin weight in each lamina. The carbon-fiber reinforced prepregs are 24-inch wide VTM 264/792/HTR40$300 \mathrm{gsm} 36 \% \mathrm{RW}$. VTM 264 is a variable temperature, vacuum processable epoxy resin developed by Cytec, HTR4O is the identification number of Toho Tenax continuous fiber reinforcement, 300 GSM denotes 300 grams per square meter areal mass of the aforementioned fiber reinforcement, and $36 \% \mathrm{RW}$ denotes resin weight in each lamina. The composite laminates 
are manufactured by curing the prepregs under pressure in a high temperature oven at $100{ }^{\circ} \mathrm{C}$. The thickness of each cured lamina is calculated using

$$
\text { Cured Ply Thickness }=\frac{\text { Fiber Areal Weight }\left(\mathrm{g} \cdot \mathrm{m}^{-2}\right)}{\text { Fiber density }\left(\mathrm{g} \cdot \mathrm{cm}^{-3}\right) \times \text { Fiber Volume }(\%) \times 10} \text {, }
$$

giving a cured ply thickness of approximately $0.23 \mathrm{~mm}$ per layer or lamina. Each composite laminate is constructed by stacking unidirectional prepregs in the required orientations to create a dense, thick laminate with a total thickness of $6.5 \mathrm{~mm}$. The layups studied in this analysis are biaxial (0/90), quasi-isotropic (0/-45/45/90), unidirectional with fibers perpendicular to supports (90) and unidirectional with fibers parallel to supports (0). Figure 1 shows the simply-supported planar impulsive loading configuration and the different layups used in laminate construction. 


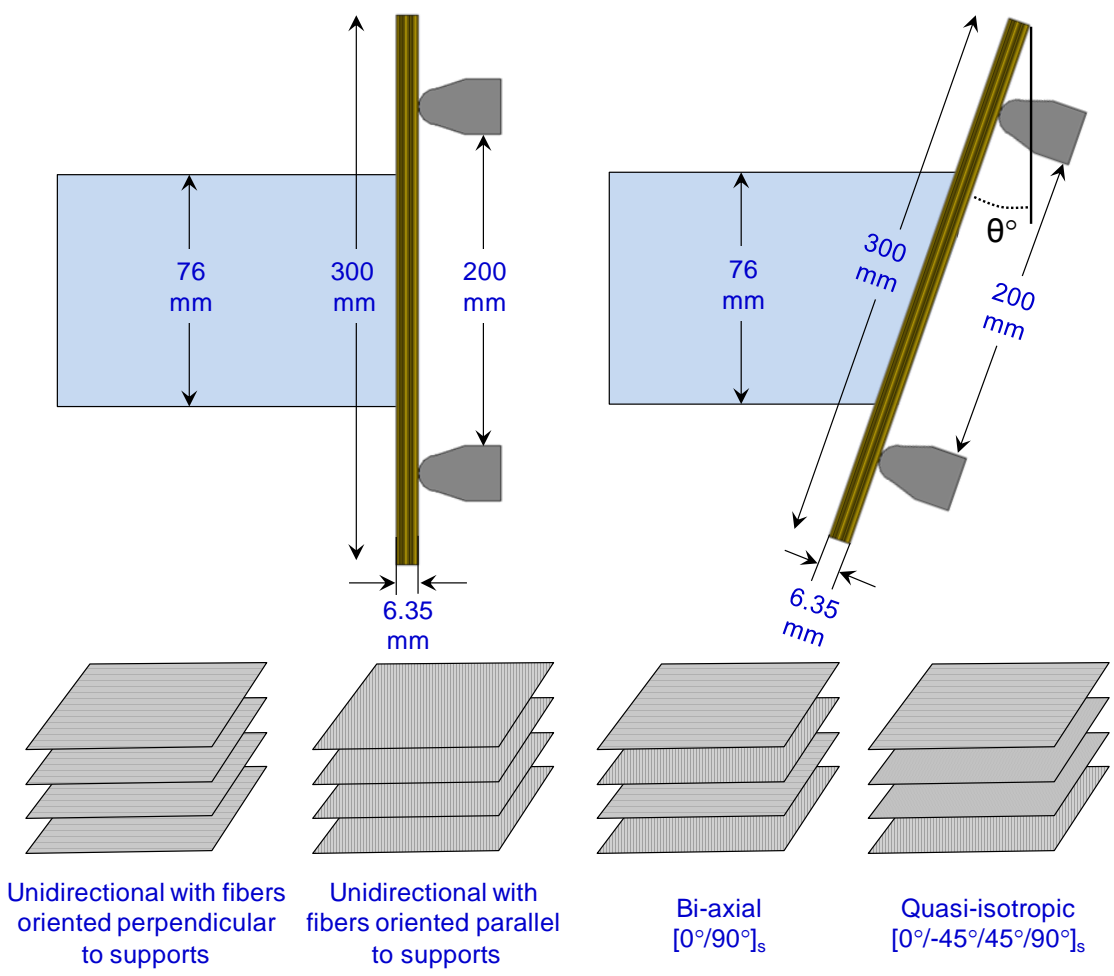

Figure 1 Schematic illuistration showing the simply-supported loading configuration with planar incident impulsive load and different composite layups of the test specimens.

Marine vessels consist of geometrical nonlinearities like inclined and curved surfaces. Such sections interact with high intensity impulsive loads rather differently from the way planar sections do under normal load incidence. The deformation and damage due to such geometric factors need to be considered for effective structure design. However, this aspect of underwater blast response has not been analyzed in the past. To evaluate the effects of load obliquity on the dynamic response of composite laminates, the loading angle is varied from $0^{\circ}$ to $10^{\circ}$ with increments of $2^{\circ}$ and each configuration is subjected to similar incident loads. Figure 1 illustrates such a loading configuration with a quasi-isotropic laminate. 


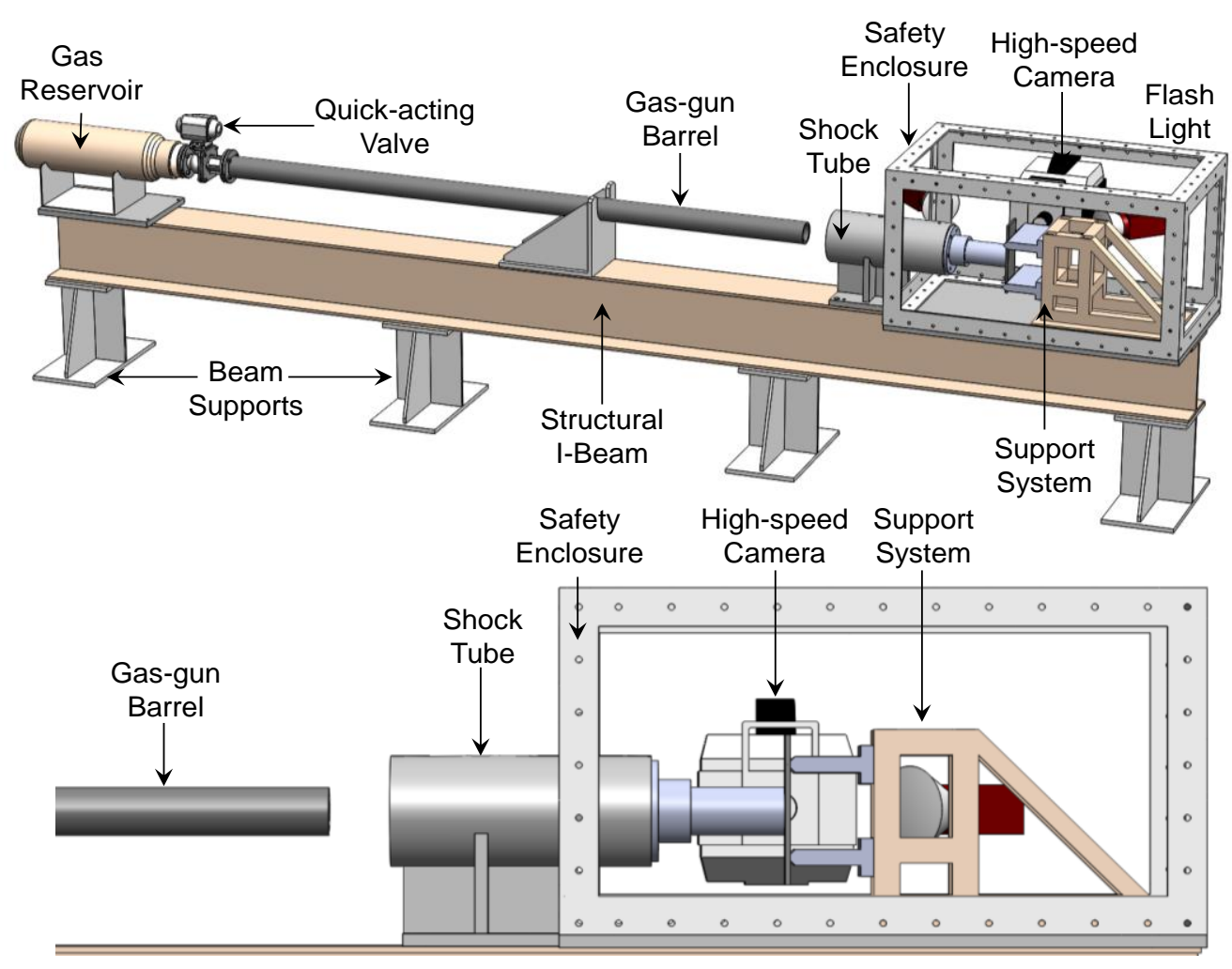

Figure 2 Schematic illustration of the Underwater Shock Loading Simulator (USLS) for testing simply-supported thick laminates. Pictured are the gas reservoir, gun barrel, water chamber, modular support system, specimen and the Imacon 200D high-speed camera.

\subsection{Water-based impulsive loading experiments}

Gas gun impact has been successfully used to generate impulsive loading through water [9, 21-24]. To obtain controlled loading and simulate different water-structure contact conditions, the Underwater Shock Loading Simulator (USLS) in Figure 2 is designed to provide a variety of loading configurations with quantitative diagnostics [21-23]. Important features of this facility include the ability to generate water-based impulsive loading of a wide range of intensity, the ability to simulate the loading of submerged structures, and integrated high-speed photographic and laser interferometric diagnostics. The impulsive load that impinges on the target induces deformation in the specimen at strain rates up to $10^{4} \mathrm{~s}^{-1}$. Projectile impact velocities in the range of $15-150 \mathrm{~ms}^{-1}$ are used to delineate the effect of loading rate on the deformation and failure 
behavior of the structures analyzed. This velocity range corresponds to peak pressures between 15 and $200 \mathrm{MPa}$, which are comparable to pressures observed in underwater explosions [25-28].

According to Taylor's analysis of one dimensional blast waves [29] impinging on a light, rigid, free standing plate, the pressure in the fluid at a distance $r$ from an explosive source follows the relation $p(t)=p_{0} \exp \left(-t / t_{0}\right)$, where $p_{0}$ is the peak pressure, $t$ is time and $t_{0}$ is the pulse time on the order of milliseconds. The area under the pressure-time curve is the impulse carried by the wave and is given by $I_{0}=\int_{0}^{t} p(t) d t=p_{0} t_{0}$. For a free standing plate of areal mass $m$, the impulse transferred to the plate is $I_{T} / I_{0}=\psi^{(\psi / 1-\psi)}$, where $\psi=\rho_{w} c_{w} t_{0} / m$, and $\rho_{w}$ is the density of water and $c_{w}$ is the speed of sound in water. This FSI parameter is an important aspect of Taylor's analysis because it helps to delineate the effects of a pressure pulse applied instantaneously versus the effects of a pressure pulse decaying over a certain time period. It has been shown that this FSI effect can be exploited to improve the blast mitigation capability of structures subjected to transient loads [30,31].

\subsection{Modeling of water-structure interaction}

The model consists of a Lagrangian domain for composite materials and an Eulerian domain for water. In the Lagrangian domain, nodes are fixed within the material and nodal displacements track the material deformation. Since each Lagrangian element is always 100\% within a single material, the material boundary coincides with element boundaries. In contrast, the Eulerian the domain consists of nodes that are fixed in space and the material flows through the elements that do not experience deformation. Eulerian elements may also be partially or completely void, allowing material to flow into empty space, capturing a crucial aspect of fluid 
flow. Materials tracked by Eulerian elements can interact with Lagrangian elements through Eulerian-Lagrangian contact algorithms to allow fully coupled multi-physics simulations like fluid-structure interactions. This Coupled Eulerian-Lagrangian (CEL) framework allows the severe deformation in water and the FSI to be captured. In addition to simulating the blast wave propagation in the USLS, the Eulerian formulation also captures the exponentially decaying pressure waves and resulting cavitation at the fluid-structure interface. The interaction between the water and structure is effected by coupling the nodes in the water to the corresponding nodes of the structure, thereby ensuring continuity of displacements when contact occurs.

The response of water in the Eulerian domain is described by the Mie-Grüneisen equation of state

$$
p=\frac{\rho_{0} c_{0}{ }^{2} \eta}{(1-s \eta)^{2}}\left(1-\frac{\Gamma_{0} \eta}{2}\right)+\Gamma_{0} \rho_{0} E_{m},
$$

where $p$ is pressure, $c_{0}$ is the speed of sound, $\rho_{0}$ is initial density, $E_{m}$ is internal energy per unit mass, $\Gamma_{0}$ is Grüneisen's Gamma at a reference state, $s=d U_{s} / d U_{p}$ is the Hugoniot slope coefficient, $U_{s}$ is the shock wave velocity, and $U_{p}$ is particle velocity which is related to $U_{s}$ through a linear Hugoniot relation

$$
U_{S}=c_{0}+s U_{p} .
$$

The parameters for the Mie-Grüneisen equation of state are listed in Table 1. The space enclosed by the shock-tube is prescribed the properties of water while the space that is outside the shocktube is kept as a "void", allowing water to flow into it as a result of high-pressure wave impinging on the target. This has the effect of instantaneously relieving the pressure in the water- 
chamber in a manner consistent with experimental observations. In the case of specimen rupture, the CL framework allows water to flow out of the breached portion.

Table 1 Parameters for the Mie-Gruneisen equation of state for water

\begin{tabular}{|c|c|c|c|}
\hline Parameter & Symbol & Unit & Value \\
\hline Density of water & $\rho$ & $\mathrm{kg} / \mathrm{m}^{3}$ & 1000 \\
\hline Speed of sound in water & $c$ & $\mathrm{~m} / \mathrm{s}$ & 1482 \\
\hline Gruneisen's Gamma & $\Gamma_{0}$ & - & 0.1 \\
\hline
\end{tabular}

\subsection{Modeling of in-ply cracking and failure}

Based on the energy required for initiation, matrix damage through cracking occurs first, followed by combined fiber-matrix debonding or "fiber-pullout" and finally fiber fracture. Damage occurring in the facesheets is accounted for using an energy-based damage evolution law [32] and [33]. The models assume a transversely isotropic solid which is perfectly elastic until the onset of damage. After damage initiation, following damage modes are accounted for through the simulatons: (1) matrix tension; (2) matrix compression; (3) fiber tension; and (4) fiber compression. The parameters used in these calculations can be found in [34] and [35]. In the simulations, a material-point has an initial, undamaged value of 1 and as the material-point experiences damage, this value decreases. The lowest value, before the material-point is removed from the simulation, is 0 . The material properties of glass-fiber reinforced epoxy and carbonfiber reinforced epoxy are provided in Table 2 and Table $3[36,37]$, respectively.

Table 2 Material properties for unidirectional glass-fiber/epoxy laminates in [34]

\begin{tabular}{|c|c|c|c|}
\hline Parameter & Symbol & Unit & Value \\
\hline Density & $\rho$ & $\mathrm{kg} \cdot \mathrm{m}^{-3}$ & 1850 \\
\hline Tensile modulus & $E_{11}$ & $\mathrm{MPa}$ & 39000 \\
\hline Transverse modulus & $E_{22}$ & $\mathrm{MPa}$ & 9000 \\
\hline
\end{tabular}




\begin{tabular}{|c|c|c|c|}
\hline Shear modulus & $G_{12}, G_{13}$ & $\mathrm{MPa}$ & 3500 \\
\hline Longitudinal tensile strength & $T_{11}$ & $\mathrm{MPa}$ & 1200 \\
\hline Longitudinal Compressive Strength & $C_{11}$ & $\mathrm{MPa}$ & 900 \\
\hline Transverse tensile strength & $T_{22}$ & $\mathrm{MPa}$ & 45 \\
\hline Transverse compressive strength & $C_{22}$ & $\mathrm{MPa}$ & 128 \\
\hline Longitudinal shear strength & $S_{12}, S_{21}$ & $\mathrm{MPa}$ & 51 \\
\hline Transverse shear strength & $S_{23}$ & $\mathrm{MPa}$ & 51 \\
\hline
\end{tabular}

Table 3 Material properties for unidirectional carbon-fiber/epoxy laminates [35]

\begin{tabular}{|c|c|c|c|}
\hline Parameter & Symbol & Unit & Value \\
\hline Density & $\rho$ & $\mathrm{kg} \cdot \mathrm{m}^{-3}$ & 1580 \\
\hline Longitudinal tensile modulus & $E_{11}$ & $\mathrm{MPa}$ & 138000 \\
\hline Transverse tensile modulus & $E_{22}$ & $\mathrm{MPa}$ & 10000 \\
\hline Shear modulus & $G_{12}, G_{13}$ & $\mathrm{MPa}$ & 5240 \\
\hline Longitudinal tensile strength & $T_{11}$ & $\mathrm{MPa}$ & 2280 \\
\hline Longitudinal compressive strength & $C_{11}$ & $\mathrm{MPa}$ & 1440 \\
\hline Transverse tensile strength & $T_{22}$ & $\mathrm{MPa}$ & 57 \\
\hline Transverse compressive strength & $C_{22}$ & $\mathrm{MPa}$ & 228 \\
\hline Longitudinal shear strength & $S_{12}, S_{21}$ & $\mathrm{MPa}$ & 71 \\
\hline Transverse Shear strength & $S_{23}$ & $\mathrm{MPa}$ & 71 \\
\hline
\end{tabular}

Table 4 Material properties for epoxy [38]

\begin{tabular}{|c|c|c|c|}
\hline Parameter & Symbol & Unit & Value \\
\hline Normal stiffness & $K_{n}$ & $\mathrm{MPa}$ & 2000 \\
\hline Shear stiffness & $K_{s}, K_{t}$ & $\mathrm{MPa}$ & 2000 \\
\hline Critical normal traction & $t_{\mathrm{n}}^{0}$ & $\mathrm{MPa}$ & 50 \\
\hline Critical shear traction & $t_{\mathrm{s}}^{0}, t_{\mathrm{t}}^{0}$ & $\mathrm{MPa}$ & 50 \\
\hline Critical normal fracture energy & $G_{n}^{C}$ & $\mathrm{~N} / \mathrm{mm}$ & 4.0 \\
\hline Critical shear fracture energy & $G_{s}^{C}, G_{t}^{C}$ & $\mathrm{~N} / \mathrm{mm}$ & 4.0 \\
\hline
\end{tabular}


To alleviate mesh dependency during material softening, Abaqus introduces a characteristic length into the formulation, so that the constitutive law is expressed as a stressdisplacement relation. The characteristic length, $L_{C}$, is based on the element geometry and formulation: it is a typical length of a line across an element for a first-order element. The damage variable will evolve such that the stress-displacement behaves as shown in in each of the four failure modes. The positive slope of the stress-displacement curve prior to damage initiation corresponds to linear elastic material behavior; the negative slope after damage initiation is achieved by evolution of the respective damage variables according to the equations shown below. For each failure mode the energy dissipated due to failure, which corresponds to the area of the triangle OAC, must be specified.

\subsection{Modeling of interfacial effects using cohesive elements}

In the simulations, each unidirectional lamina is simulated explicitly to accurately represent the structure and behavior of the entire carbon-fiber/epoxy laminate and capture damage and deformation. The epoxy layers between two laminas, also called "resin rich layers", are modeled using cohesive elements to capture interfacial fracture and delamination. Due to the inherently heterogeneous nature of fiber-reinforced composites, interfacial separation plays a very important role in deformation. Interfacial separation of directionally stacked layers in the composite is called delamination. Delamination requires very little energy and is the dominant damage mode in composite materials subjected to impact or impulsive loads. It occurs primarily due to matrix failure and matrix-finer separation and reinforcing fibers are relatively intact. Similarly, core-facesheet separation is an important damage mode that occurs due to interfacial separation and fracture. If the bond between facesheet and core is weak, interfacial separation occurs. If the bond between the facesheet and the core is strong, tensile fracture in the foam leads 
to separation. Some commonly used metrics to evaluate the damage resistance of composites to impact loads are impact energy, displacement, delamination-area and extent of rupture.

The cohesive finite element method (CFEM) has been extensively used to study a wide variety of issues related to delamination and fracture such as tensile decohesion (Needleman [39]), quasi-static crack growth (Tvergaard and Hutchinson[40]), ductile fracture (Tvergaard and Needleman [41, 42]), dynamic fracture (Xu and Needleman [43]), dynamic fragmentation (Camacho and Ortiz [44], Espinosa et al. [45]), delamination in composites (Camanho et al. [46], Minnaar and Zhou [47]) and microstructural fracture (Zhai and Zhou [48]). Here, cohesive elements are specified at the interfaces between individual laminas in the composite structure as well as the interfaces between the aluminum and composite sections in the hybrid plates. The cohesive elements allow damage initiation and development in the interlaminar regions to be captured.

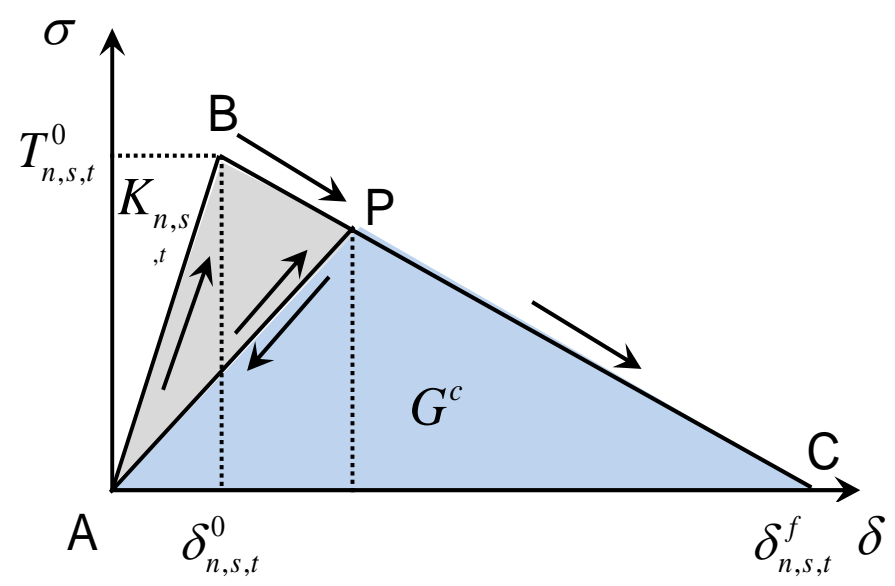

Figure 3 Bi-linear law for cohesive traction-separation behavior.

A bilinear traction-separation law shown in Figure 3 is adopted to describe the behavior of the cohesive elements [46]. The parameters for all cohesive relations used are obtained from the work performed by Lapczyk and Hurtado [38] and are presented in 
Table 4. The traction-separation stiffness for cohesive elements along interfaces between the laminas is $10^{3}$ times the stiffness of the corresponding bulk elements. This choice has two benefits. First, artificial softening of the model is avoided. Second, the work of separation associated with the linear-elastic portion of the cohesive behavior is minimized, ensuring that the bulk of the work is in the fracture energy, providing adequate softening in the cohesive response. After failure of cohesive elements, contact between element faces is considered in the model using the a contact algorithm similar to that developed by Camacho and Ortiz [44]. If penetration is predicted, then penalty forces of sufficient magnitude are applied to the surfaces in the direction of their normal such that there is contact between them but minimum or no interpenetration.
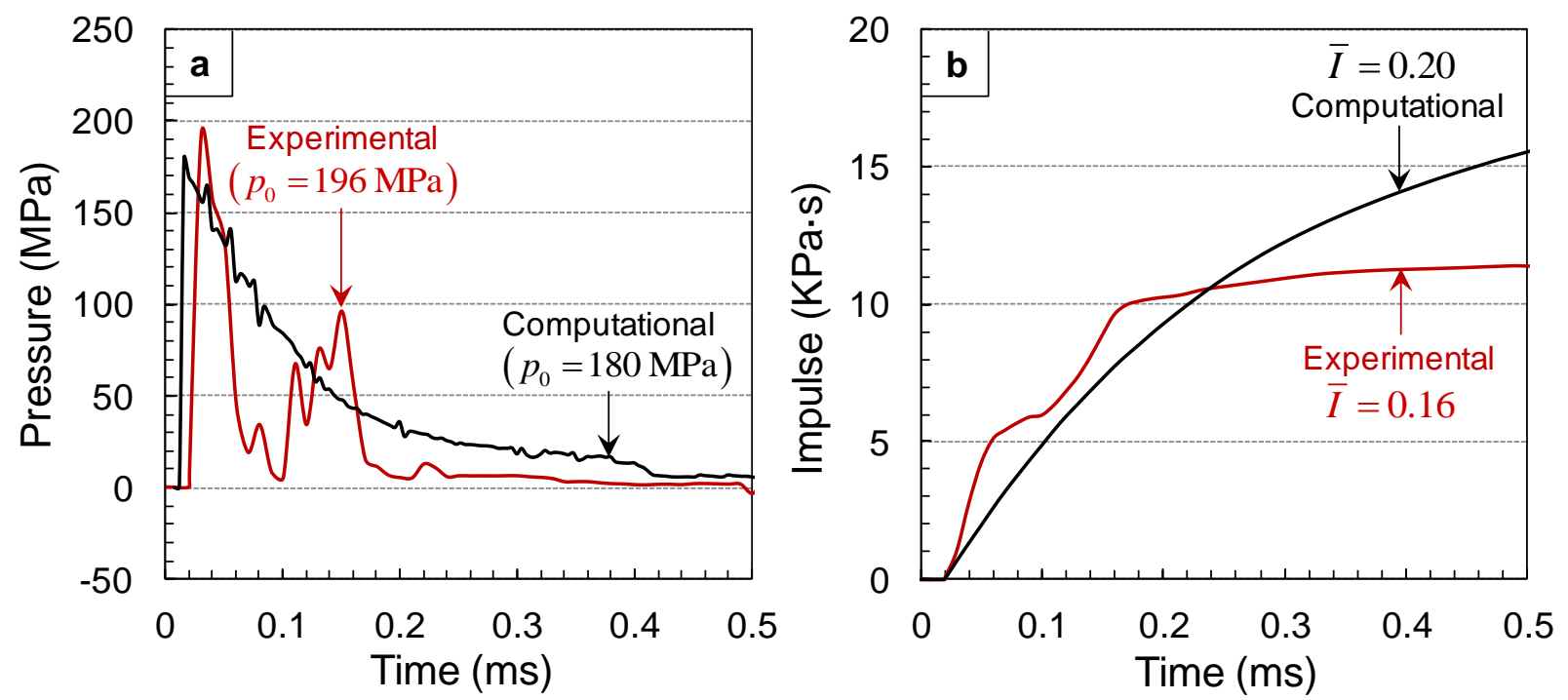

Figure 4 Experimentally measured and numerically calculated pressure and impulse histories in the water chamber for a gas reservoir base pressure of $350 \mathrm{psi}$ and a projectile velocity of $\sim 110$ $\mathrm{ms}^{-1}$.

The experimentally measured and calculated pressure pulses show good agreement in terms of peak pressures and decay times, as shown in Figure 4. The experimentally measured profiles show slightly faster wave attenuation than the calculated profiles. Clearly, the coupled 
Eulerian-Lagrangian framework and the Mie-Gruneisen equation of state allow most essential features of the loading pulses in the experiments to be captured. Although the peak pressures are similar for experiments and simulations, the decay times are slightly different. The normalized impulse magnitude is $\bar{I}=0.20$ for experiments and $\bar{I}=0.16$ for simulations.

A laminate is discretized into two distinct interacting phases: (1) fiber-reinforced phase in the in-ply or intralaminar regions which are simulated using 3-D brick elements; and (2) resinrich phase in the inter-ply or interlaminar regions which are simulated using cohesive finite elements of finite thickness. Failure is predicted when the damage operator in the respective case reaches unity. Once this rupture criterion is satisfied, the properties of failed elements are modified so that only compressive stresses are supported and tensile and shear stresses are eliminated. However, the predictions of damage and structural response based on such failure criteria are inherently mesh-size dependent as shown by Needleman and Tvergaard [42] and Gullerud et al. [49]. When the stress-strain diagram exhibits a negative slope, the strain-softening damage tends to localize in a zone that is governed by element size. Since the damage dissipation per unit volume is finite, the vanishing damage zone causes the structure to fail at zero energy dissipation. In the current computational approach, the mesh size selection must ensure satisfactory strain resolution, realistic energy dissipation and must qualitatively reflect the experimentally observed deformation modes. To counteract this spurious mesh dependence associated with material softening, a characteristic element length $L_{E}$ is introduced in ABAQUS. For 3-D elements, $L_{E}$ is the cube-root of element volume. Following damage initiation, an equivalent displacement $\delta$ is introduced such that $\delta=L_{E} \cdot \varepsilon$ and evolves according to $\dot{\bar{\delta}}=L_{E} \cdot \dot{\bar{\varepsilon}}$ until it reaches a critical value. Although mesh refinement is essential for adequate strain 
resolution, excessive mesh refinement has the adverse effect of yielding anomalously low energy dissipation. As shown in Figure 5, the numerical solution reaches convergence for a mesh width of $w=500 \mu \mathrm{m}$. Consequently, the mesh width selected for this calculation is $w=500 \mu \mathrm{m}$, which is sufficient for numerical convergence (in both, bulk and cohesive elements) but still provides a reasonable approximation of energy dissipated in the process. These element sizes are in accordance with element size recommendations from Tomar et al. [50] for cohesive elements.

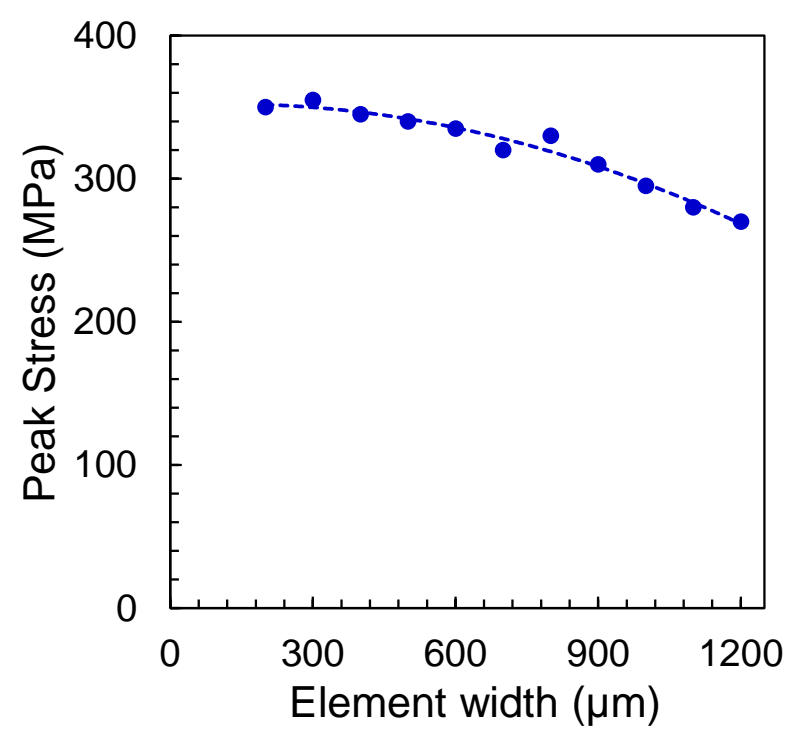

Figure 5 Peak stress in the laminate as a function of element size for impulsively loaded composite laminates.

\section{Results and discussion}

\section{$\underline{3.1 \text { Experiments and validation of model }}$}

The deformation in a dynamically loaded composite laminate can be divided into two regimes: (1) flexural wave propagation towards the supports and (2) structural deflection. The flexural wave travels towards the supports in a very short time $(\sim 50 \mu \mathrm{s})$. Although the resolution of the camera is sufficient to capture this phenomenon, we are more interested in structural response in the form of damage and out-of-plane deflection, which take place over a longer time 
span. Consequently, the temporal resolution of the camera is selected to capture the behavior over a duration of 2 milliseconds. The experiments and simulations are considered together in order to develop a detailed analysis and intimate understanding of structural failure in blastloaded monolithic composite plates. Both quantitative and qualitative approaches are used to evaluate blast response.

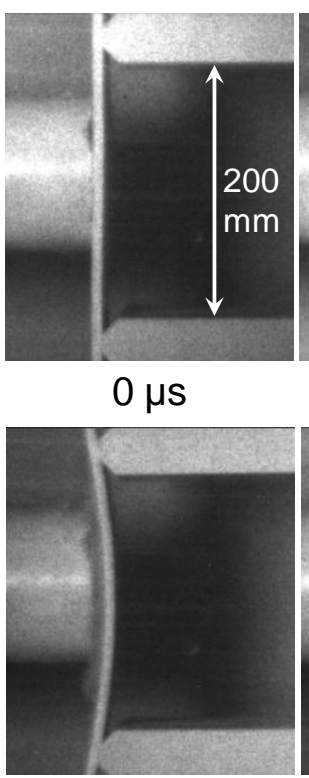

$800 \mu \mathrm{s}$

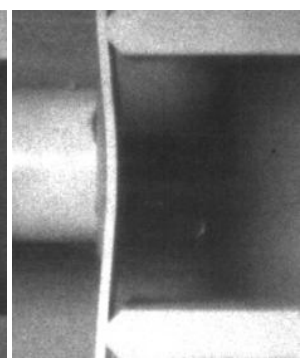

$200 \mu s$

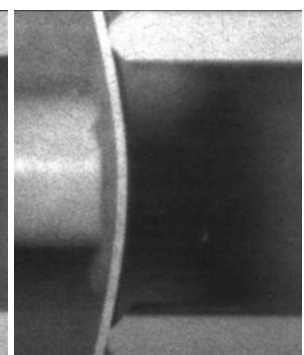

$1000 \mu \mathrm{s}$

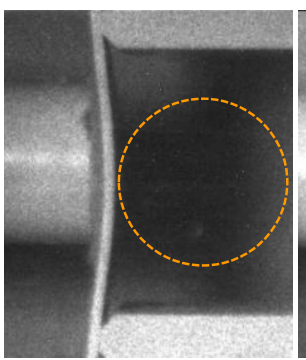

$400 \mu s$

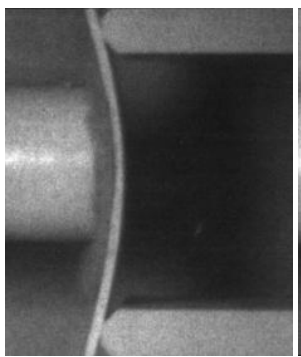

$1200 \mu \mathrm{s}$

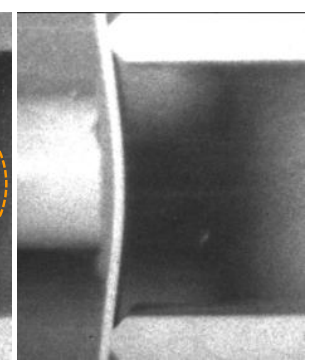

$600 \mu \mathrm{s}$

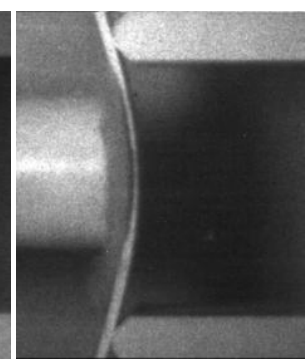

$1400 \mu \mathrm{s}$

Figure 6 Sequence of high-speed photographs showing the deformation in a monolithic carbonfiber/epoxy composite plate with a quasi-isotropic layup subjected to $\bar{I}=0.08$.

In order to accurately compare the performance of composite structures under blast loading, we need to consider laminates of equal areal mass subjected to similar incident impulses. Since quasi-isotropic laminates are most widely used in commercial applications, we identified the incident failure impulse for a $6.35 \mathrm{~mm}$ thick quasi-isotropic laminate. A number of experiments were carried out to determine that the quasi-isotropic laminate fails under an impulsive load with a peak pressure of 196 MPa. It was found that a gas reservoir base pressure of 350 psi generated an underwater pressure wave with a peak pressure of 196 MPa with a 
variation of up to $20 \mathrm{MPa}$. Although the peak pressures are similar for experiments and simulations, the decay times are slightly different. The normalized impulse magnitude is $\bar{I}=$ 0.20 for experiments and $\bar{I}=0.16$ for simulations.

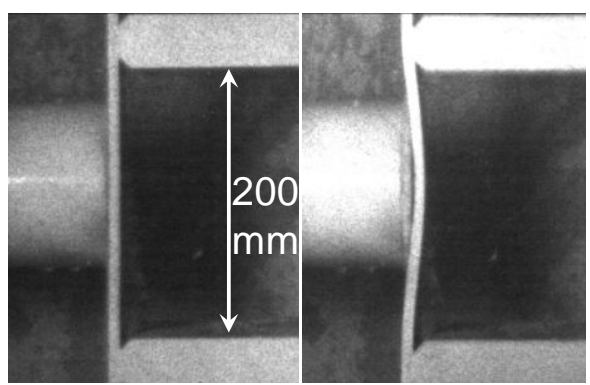

$0 \mu \mathrm{s}$

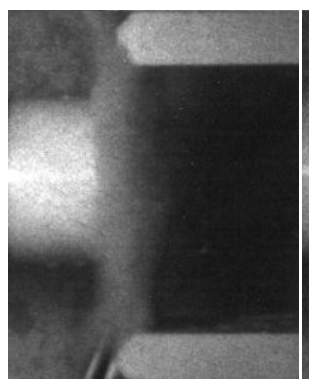

$800 \mu \mathrm{s}$
$200 \mu \mathrm{s}$

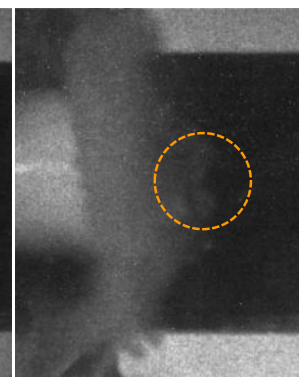

$1000 \mu \mathrm{s}$

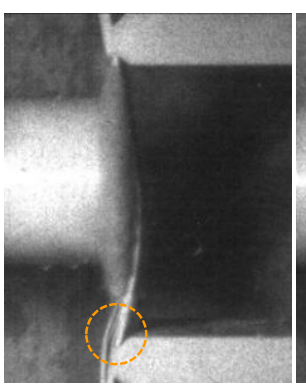

$400 \mu \mathrm{s}$

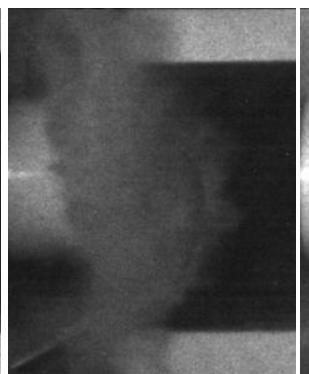

$1200 \mu \mathrm{s}$

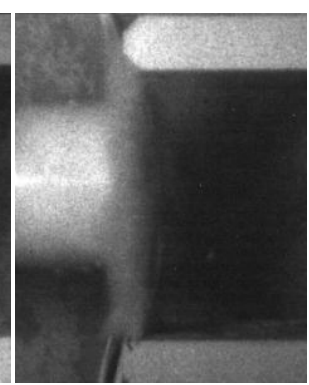

$600 \mu \mathrm{s}$

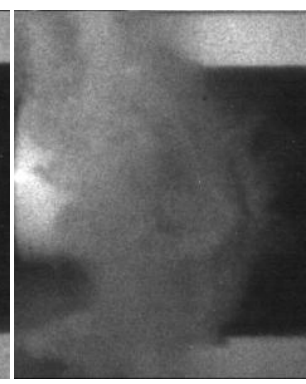

$1400 \mu \mathrm{s}$

Figure 7 Sequence of high-speed photographs showing the deformation in a monolithic carbonfiber/epoxy composite laminate with a biaxial layup subjected to $\bar{I}=0.16$.

As discussed previously, the loading configuration consists of a simply supported composite beam which undergoes bending deformation. The magnitude and rate of bending is determined by the incident impulse. Figure 6 shows a sequence of high-speed photographs showing the deformation in a monolithic carbon-fiber/epoxy composite laminate with a quasiisotropic layup subjected to $\bar{I}=0.08$. In this case, the composite laminate undergoes bending deformation, but the impulsive load is insufficient to cause failure. Since there is no failure, the water in the shock tube does not breach the laminate and instead, escapes the chamber by flowing sideways with respect to the composite, in the direction of high-speed camera. Note the 
lack of any water in the space directly behind the composite as shown at $t=400 \mu \mathrm{s}$. Figure 7 shows the sequence of high-speed photographs of deformation in a monolithic carbonfiber/epoxy composite laminate with a biaxial layup subjected to $\bar{I}=0.16$. A comparison of deformation at two different impulse magnitudes shows that at $\bar{I}=0.16$, the pressurized water breaches the composite laminate and flows through the back side of the bending plate, clearly signifying rupture and catastrophic failure. In summary, tracking the behavior of the water column in touch with the specimen using high-speed digital imaging can provide an insight into the structural response, failure modes and collapse of each composite laminate.

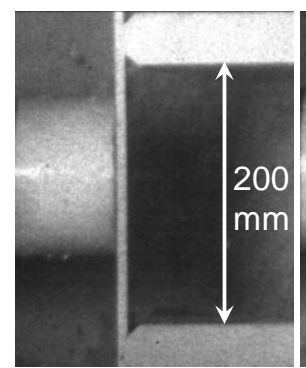

$0 \mu \mathrm{s}$

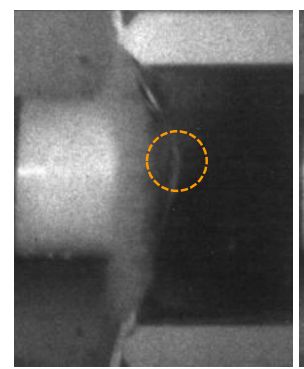

$800 \mu \mathrm{s}$

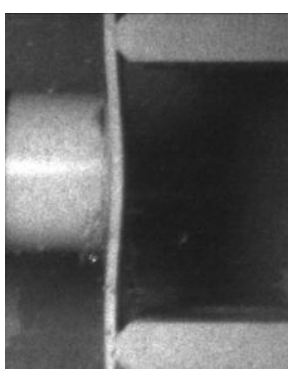

$200 \mu s$

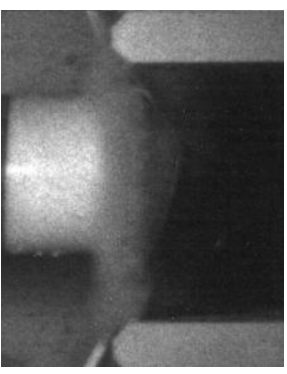

$1000 \mu \mathrm{s}$

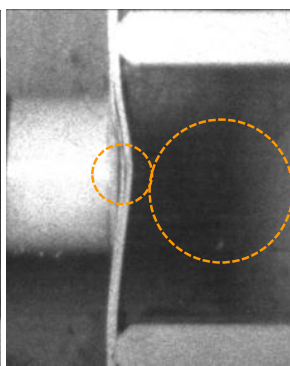

$400 \mu \mathrm{s}$

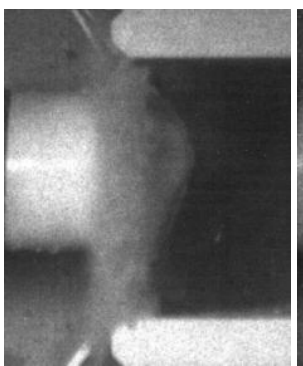

$1200 \mu \mathrm{s}$

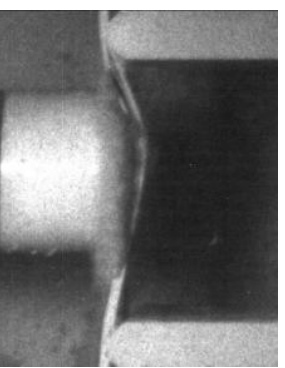

$600 \mu \mathrm{s}$

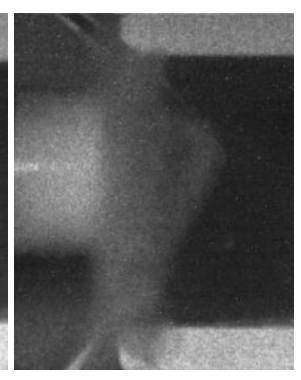

$1400 \mu \mathrm{s}$

Figure 8 Sequence of high-speed photographs showing the deformation in a monolithic carbonfiber/epoxy composite plate with a quasi-isotropic layup subjected to $\bar{I}=0.16$. 


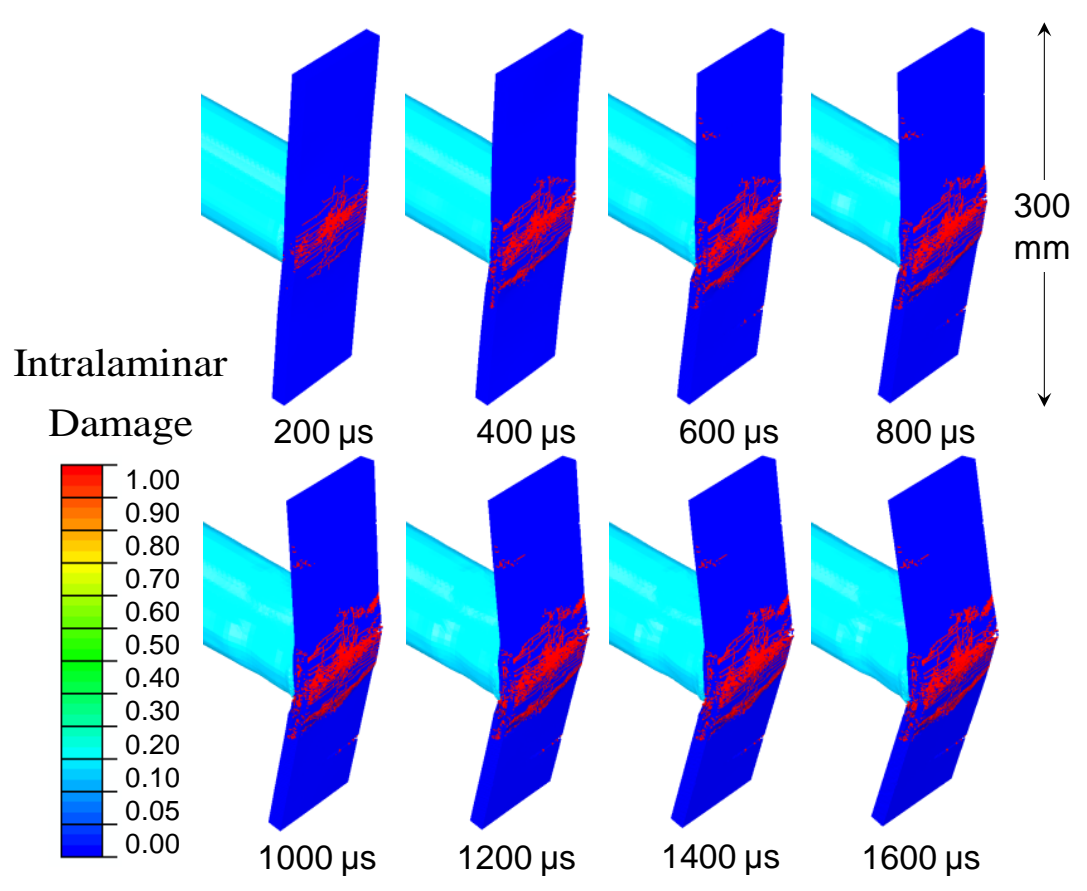

Figure 9 Distributions of in-ply damage in quasi-isotropic carbon-fiber/epoxy composite laminate subjected to $\bar{I}=0.20$.

Figure 8 shows a sequence of high-speed photographs of a quasi-isotropic carbonfiber/epoxy laminate subjected to $\bar{I}=0.16$. Figure 9 shows the in-ply damage contours for a quasi-isotropic carbon-fiber/epoxy laminate subjected to $\bar{I}=0.20$. After the onset of bending deformation at $t=200 \mu \mathrm{s}$, the quasi-isotropic plate undergoes delamination near the midplane at $t=400 \mu \mathrm{s}$. The interlaminar cracks propagate towards the supports and cause further delamination near the edge at $t=600 \mu \mathrm{s}$. Since a simply-supported loading configuration causes maximum stresses near the midplane, a "hinge" or localized deformation develops in the laminate due to a combination of compressive and tensile stresses through the thickness. This observation is supported by the computational results shown in Figure 9. It should be noted that although there is widespread delamination and in-ply damage, water flowing out of the shock tube does not breach the plate, instead flowing out of the sides as observed in Figure 6. Results 
indicate that the computational model accurately captures the deformation observed in experiments.

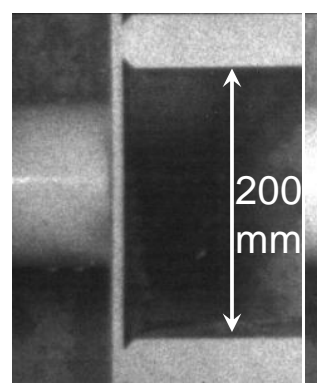

$0 \mu \mathrm{s}$

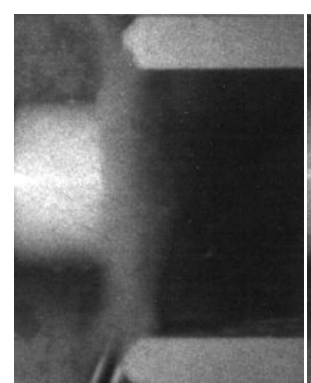

$800 \mu s$

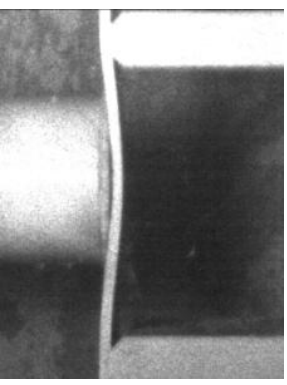

$200 \mu \mathrm{s}$

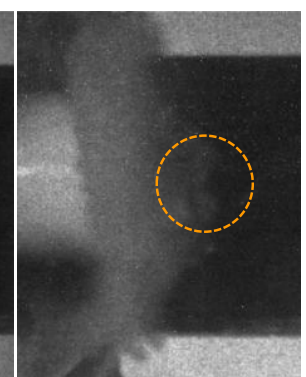

$1000 \mu \mathrm{s}$

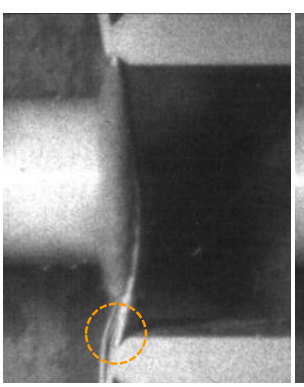

$400 \mu \mathrm{s}$

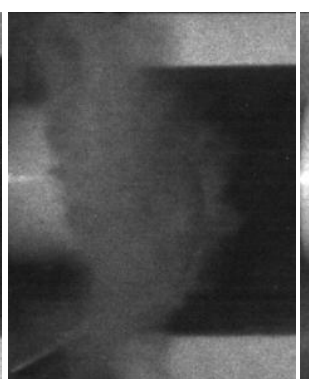

$1200 \mu \mathrm{s}$

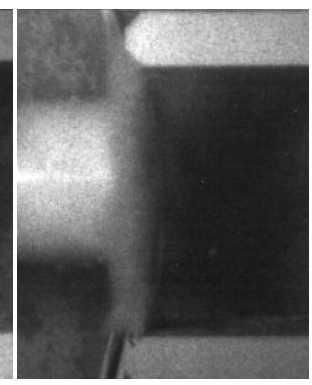

$600 \mu \mathrm{s}$

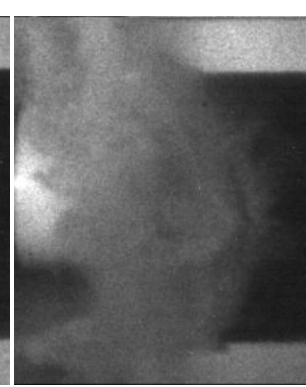

$1400 \mu \mathrm{s}$

Figure 10 Sequence of high-speed photographs showing the deformation in a monolithic carbonfiber/epoxy composite laminate with fibers oriented parallel to the supports subjected to $\bar{I}=0.16$.

As discussed previously, the quasi-isotropic layup exhibits large scale delamination but does not experience failure. In order to determine whether delamination can be localized to smaller region by modifying the laminate layup, laminates are constructed such that all laminas have fibers oriented parallel to the supports. Figure 10 shows a sequence of high-speed photographs of a carbon-fiber/epoxy laminate with fibers oriented in a direction parallel to the supports subjected to underwater impulsive loads of similar magnitudes. After the onset of bending delamination at $t=200 \mu \mathrm{s}$, the plate experiences delamination at $t=400 \mu \mathrm{s}$. After delamination initiation, the delaminated sections of the laminate experience severe bending stresses leading to in-ply rupture at $t=1000 \mu \mathrm{s}$, followed by perforation of the plate near the midplane and catastrophic failure at 
$t=1200 \mu \mathrm{s}$. The computational framework accounts for the effects of fiber orientation and captures the flow of water through the structure post-failure. Since the fibers are oriented parallel to the supports, a relatively smaller fraction of the incident impulse is transmitted to the supports leading significantly higher deflection and localized in-ply damage and fracture in close proximity to the impulsive wave loading area. Delamination is observed over a smaller area than the quasi-isotropic laminate, primarily near the loading region.

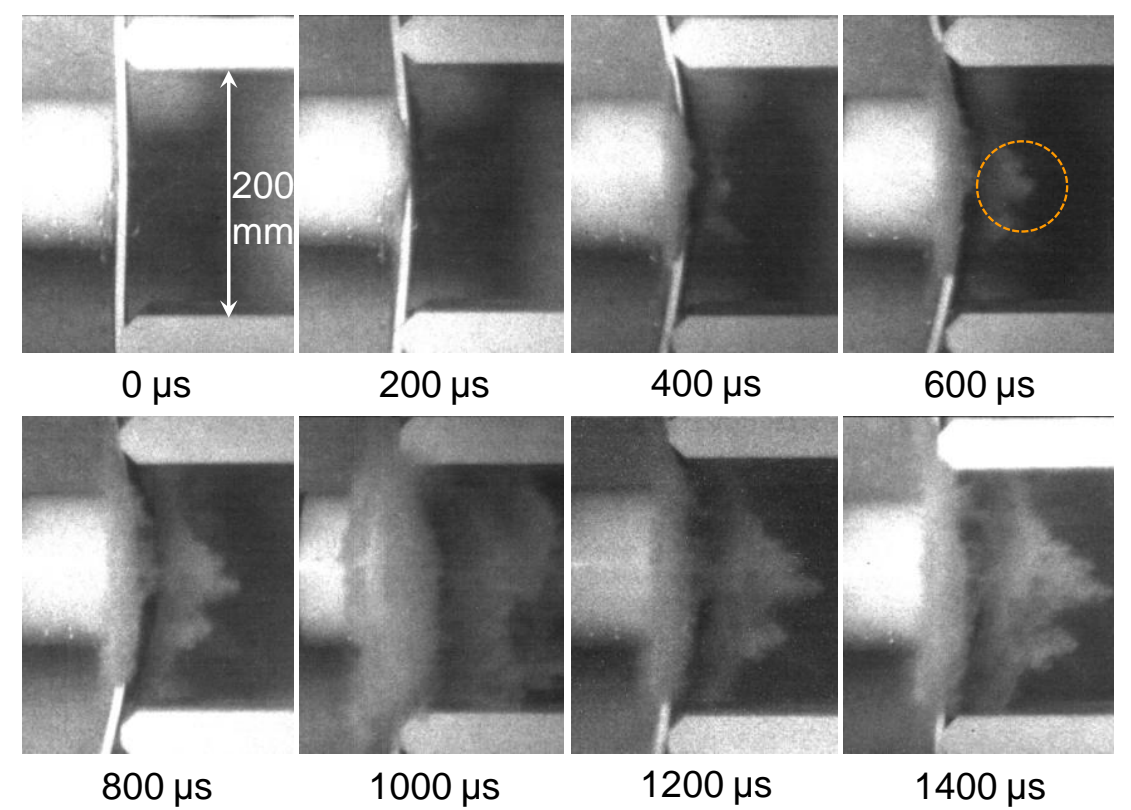

Figure 11 Sequence of high-speed photographs showing the deformation in a monolithic carbonfiber/epoxy composite laminate with fibers oriented perpendicular to the supports subjected to $\bar{I}=0.16$.

Figure 11 shows a sequence of high-speed photographs of a carbon-fiber/epoxy laminate with fibers oriented in a direction perpendicular to the supports subjected to underwater impulsive loads of similar magnitudes. In this case, the plate is extremely stiff in the vertical direction and resists bending much more than the other layups. However, the lack of bending causes high shear stresses in the laminate. Since the laminate lacks stability in the horizontal direction, the high transverse shear stresses cause "splitting" in the composite structure leading to 
failure at $t=400 \mu \mathrm{s}$. A comparison of the finite element simulations of the quasi-isotropic laminate with respect to the uniaxially oriented laminates reveals that the quasi-isotropic layup provides superior blat resistance by minimizing shear stresses in any particular region and distributing the incident impulsive load in a uniformly to avoid localized rupture.
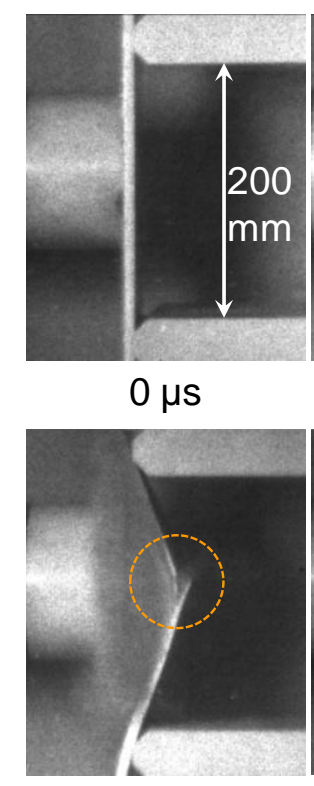

$800 \mu \mathrm{s}$

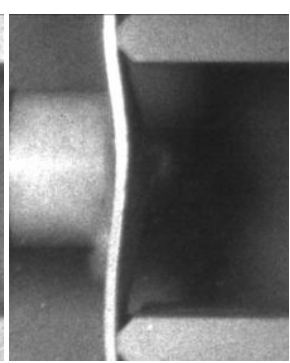

$200 \mu s$

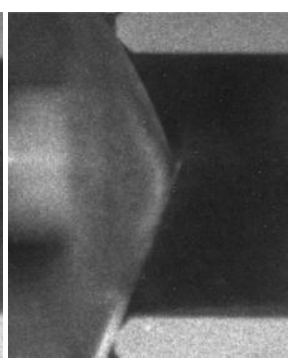

$1000 \mu \mathrm{s}$

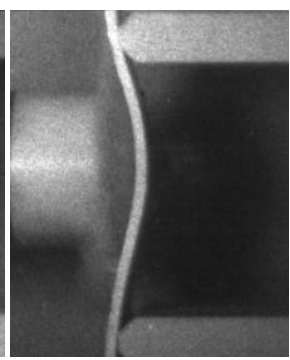

$400 \mu \mathrm{s}$

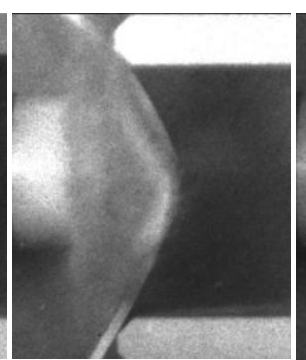

$1200 \mu \mathrm{s}$

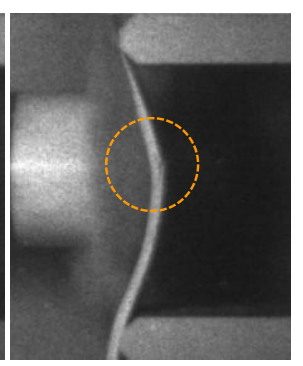

$600 \mu \mathrm{s}$

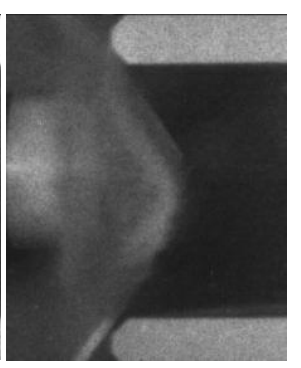

$1400 \mu \mathrm{s}$

Figure 12 Sequence of high-speed photographs showing the deformation in a monolithic glassfiber/epoxy composite laminate with a biaxial layup subjected to $\bar{I}=0.16$.

Carbon-fiber/epoxy laminates exhibit exceptionally high stiffness and bending resistance due to the high elastic modulus of carbon fibers. Investigation of the underwater blast resistance of such laminates indicates that the composite plates are quite stable and blast resistant prior to damage initiation. However, after damage initiates, the laminates experience a dramatic loss in stiffness and undergo catastrophic failure and collapse. Additionally, carbon-fiber/epoxy laminates significantly more expensive in comparison to glass-fiber/epoxy laminates. With respect to the materials studied here and reported in this analysis, the carbon-fiber/epoxy laminates have a unit cost that is more than twice as much as that of glass-fiber/epoxy laminates. 
Since marine structures often require large quantities of composite materials, cost considerations can play a major role in materials selection. To evaluate the differences in structural response of carbon-fiber and glass-fiber/epoxy laminates, a set of experiments and simulations is carried consisting of glass-fiber/epoxy laminates with different fiber layups subjected to incident impulses similar to those for the carbon-fiber/epoxy laminates. For brevity, high-speed photographs of all layups and computational results for only the quasi-isotropic layup are reported. The high-speed photographs are followed by a quantitative analysis of the blast response of both carbon-fiber and glass-fiber/epoxy laminates.

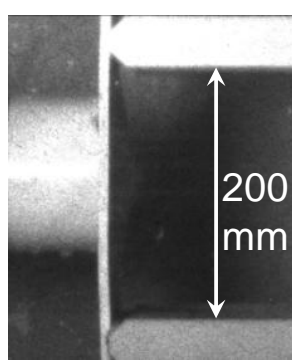

$0 \mu \mathrm{s}$

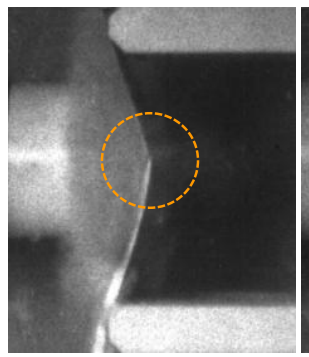

$800 \mu \mathrm{s}$

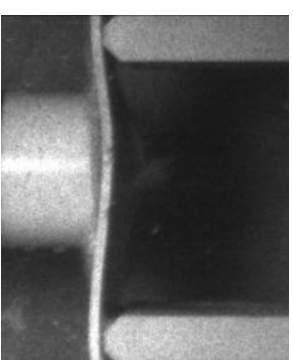

$200 \mu \mathrm{s}$

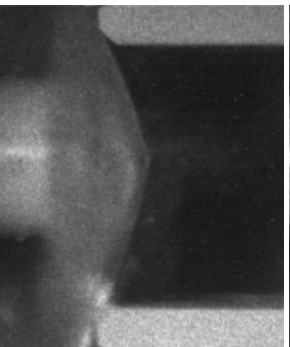

$1000 \mu \mathrm{s}$

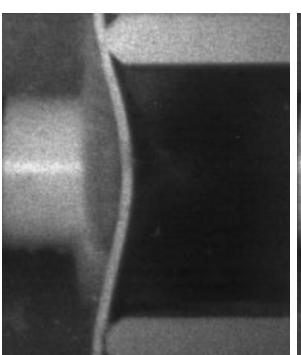

$400 \mu \mathrm{s}$

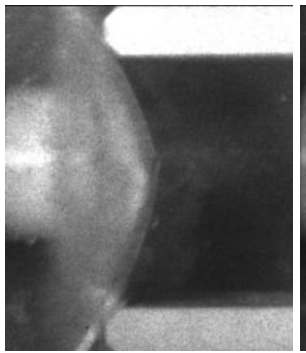

$1200 \mu \mathrm{s}$

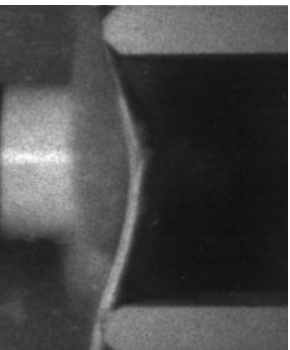

$600 \mu \mathrm{s}$

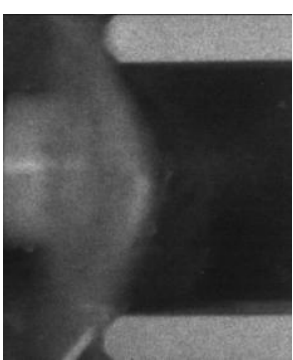

$1400 \mu \mathrm{s}$

Figure 13 Sequence of high-speed photographs showing the deformation in a monolithic glassfiber/epoxy composite laminate with a quasi-isotropic layup subjected to $\bar{I}=0.16$.

Figure 12 shows a sequence of high-speed photographs of a biaxially oriented glassfiber/epoxy laminate subjected to $\bar{I}=0.16$. After the onset of bending at $t=200 \mu \mathrm{s}$, an in-ply crack initiates at the backface and propagates towards the frontface at $t=600 \mu \mathrm{s}$. This propagating crack deflects into two interlaminar cracks at $t=800 \mu \mathrm{s}$. The composite laminate 
loses stiffness and undergoes catastrophic failure at $t=1200 \mu \mathrm{s}$. Figure 13 shows a sequence of high-speed photographs of a quasi-isotropic glass-fiber/epoxy laminate subjected to $\bar{I}=0.16$. Figure 14 shows the in-ply damage contours for a quasi-isotropic glass-fiber/epoxy laminate subjected to $\bar{I}=0.20$. The deformation in the composite plate is initially arrested as indicated by the smaller jump in displacement between $t=400 \mu \mathrm{s}$ and $t=600 \mu \mathrm{s}$ in comparison to the change in displacement between $t=200 \mu \mathrm{s}$ and $t=400 \mu \mathrm{s}$. However, at $t=800 \mu \mathrm{s}$, the deforming laminate experiences cracking at the backface and a $45^{\circ}$ crack travels from the backface to the frontface.

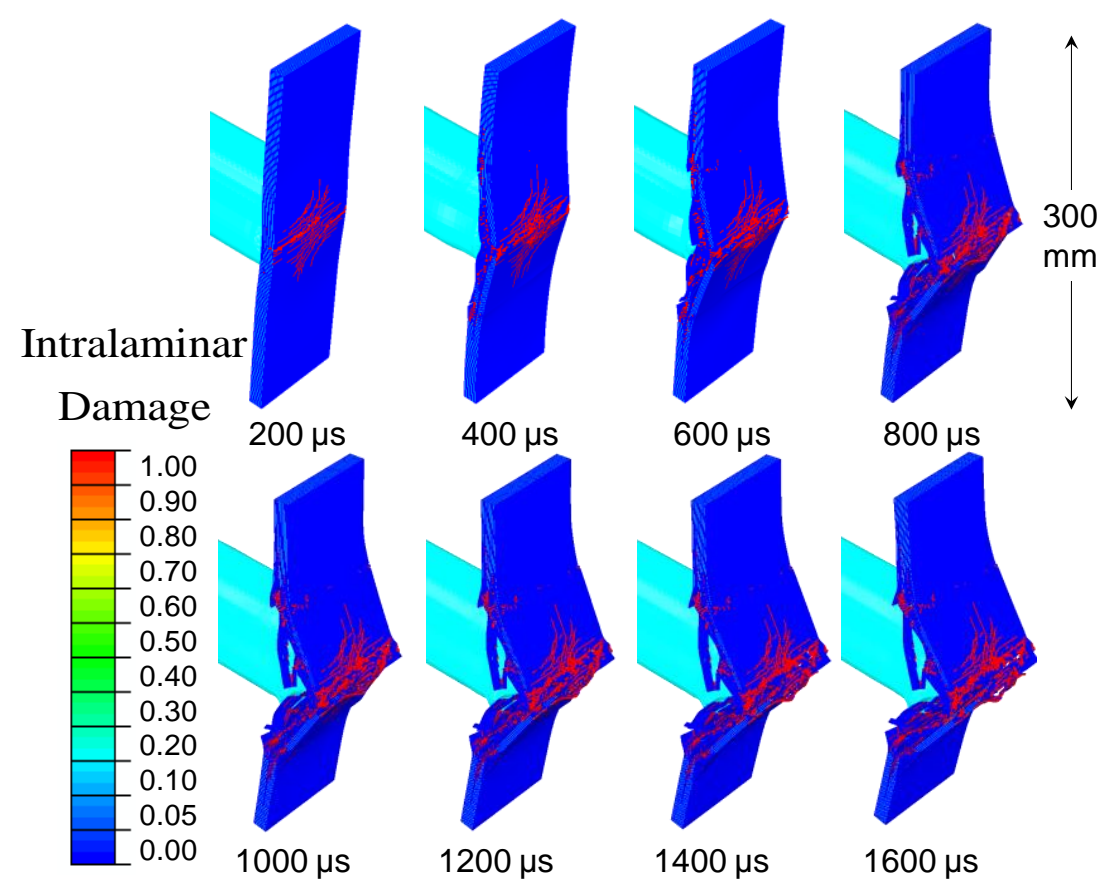

Figure 14 Distributions of in-ply damage in a quasi-isotropic glass-fiber/epoxy composite laminate subjected to $\bar{I}=0.20$.

Comparing the computational results for the carbon-fiber laminate and glass-fiber laminate shows that the glass-fiber composite plate experiences significantly greater out-of-plane deflection for similar applied impulse. Since the tensile stresses created in a bending plate are 
strongly dependent on out-of-plane deflection, the glass-fiber laminate primarily undergoes damage and cracking at the midsection. Additionally, interlaminar damage, fracture, and separation are restricted to the region close to the center of the plate. Figure 15 shows the experimental and computational out-of-plane deflection histories for carbon-fiber/epoxy laminates with different layups. The quasi-isotropic laminate experiences the least deflection, followed by the biaxial laminate, laminate with fibers oriented perpendicular to supports, and parallel to supports, in that order. Initially, the rate of deformation for all plates is similar but as the deformation progresses. As deformation progresses, the quasi-isotropic and biaxial laminates experience a reduction in the rate of bending at $t=800 \mu \mathrm{s}$.
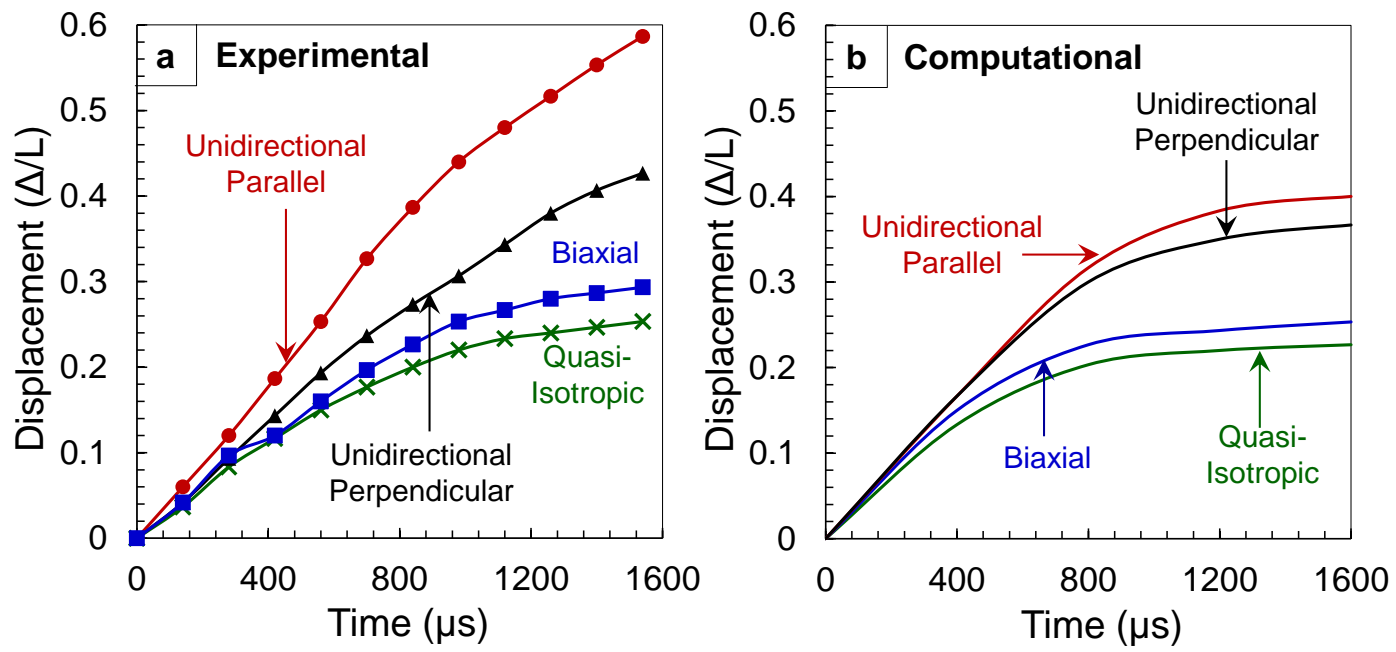

Figure 15 Experimentally measured and numerically calculated midpoint displacements as functions of time for carbon-fiber/epoxy laminates to similar incident impulsive loads.

Laminates with fibers oriented parallel to the supports exhibit the least blast resistance, due to their inability to transmit the incident impulse to the supports and mitigate the effects of incident impulsive loads. The laminate with fibers oriented parallel to the supports undergoes the greatest deflection, with a normalized deflection $(\Delta / L)$ of 0.6 . The laminate with fibers oriented 
perpendicular to supports undergoes $60 \%$, the biaxial plate undergoes $50 \%$, and the quasiisotropic plate experiences $40 \%$ of the deflection experienced by the laminate with fibers oriented parallel to the supports. The computational model accounts for the essential aspects of deformation but the continuum damage framework underestimates the stiffness of the plate resulting in artificial softening which leads to a lower rate of deformation post-failure in comparison to the experiments. However, the model accurately captures the relative blast resistance of each composite laminate.
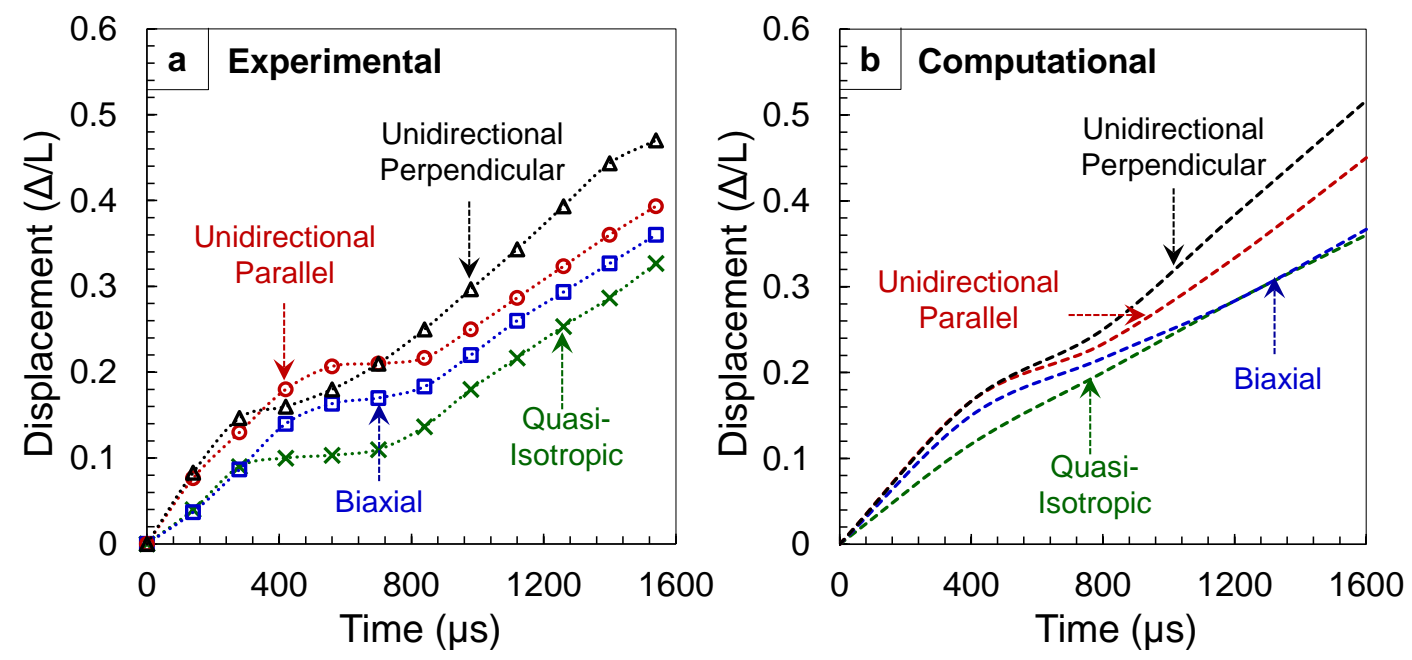

Figure 16 Experimentally measured and numerically calculated midpoint displacements as functions of time for glass-fiber/epoxy laminates to similar incident impulsive loads.

\subsection{Out-of-plane deflection}

The out-of-plane deflection histories of glass-fiber/epoxy laminates with different fiber layups are shown in Figure 16. Glass-fibers are inherently more compliant, possessing approximately $30 \%$ of the stiffness and strength of carbon-fibers despite being $20 \%$ heavier by weight. This is reflected in the deflection of the glass-fiber/epoxy plates which show a clear softening behavior under water-based impulsive loading. The quasi-isotropic laminate experiences the least deflection, with a normalized deflection $(\Delta / L)$ of 0.35 with the biaxial 
plate experiencing $10 \%$ more deflection, the plate with fibers oriented parallel to supports experiencing $20 \%$ more deflection, and fiber oriented perpendicular to supports experiencing $40 \%$ more deflection. The rate of impulse transmission and the magnitude of the transmitted impulse can provide valuable insight into the blast resistance and performance of composite structures. Figure 17(a) shows the reaction forces measured at the supports in finite element simulations while Figure 17(b) shows the corresponding impulses calculated using $I=\int F \cdot d t$.
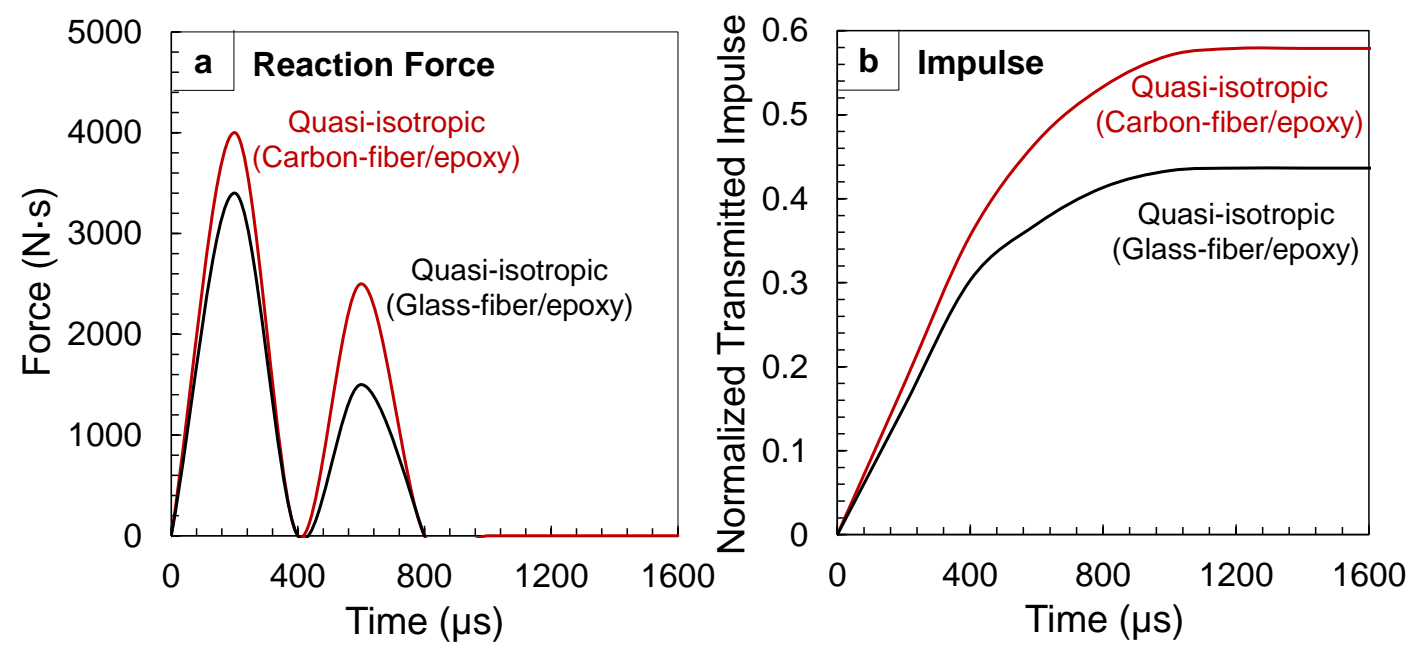

Figure 17 Calculated reaction forces and transmitted impulses as functions of time for carbonfiber/epoxy and glass-fiber/epoxy laminates subjected to similar incident impulsive loads.

The Hashin damage model used in this computational approach consists of damage modes that encompass tensile matrix cracking, compressive matrix cracking, tensile fiber cracking and compressive matrix cracking. Since cracking initiates due to high tensile stresses caused by bending, the intralaminar damage considered for the purposes of damage quantification is the tensile damage occurring in the matrix and fibers. A cohesive zone model is used to evaluate interlaminar cracking. Evaluating the rate and extent of damage can provide a deeper insight into the performance of each composite plate. In order to evaluate the total 
damage in impulsively loaded composite structures, we use a cumulative damage term called “accumulated damage" defined by $\bar{N}=$ Number of Failed Elements/Total Number of Elements .
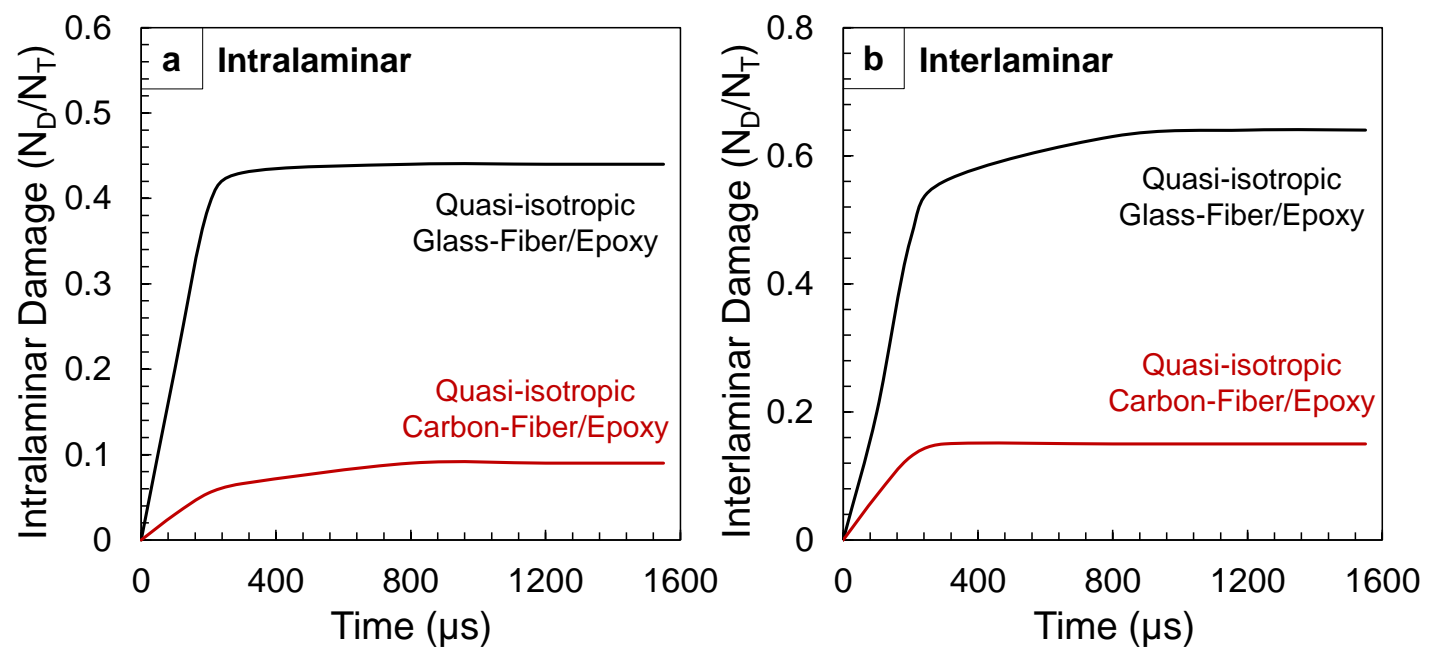

Figure 18 Calculated reaction forces and transmitted impulses as functions of time for carbonfiber/epoxy and glass-fiber/epoxy laminates subjected to similar incident impulsive loads.

Figure 18(a) shows the ratio of the number of elements undergoing intralaminar damage and the total number of elements described by the Hashin damage model as a function of time for quasi-isotropic carbon-fiber/epoxy and glass-fiber/epoxy laminates subjected to $\bar{I}=0.20$. The glass-fiber/epoxy specimen experiences damage in $\sim 40 \%$ of the laminate while the carbonfiber/epoxy specimen experiences damage in $\sim 10 \%$ of the laminate. Figure 18 (b) shows the ratio of the number of elements undergoing interlaminar damage and the total number of cohesive elements as a function of time for quasi-isotropic carbon-fiber/epoxy and glass-fiber/epoxy laminates subjected to $\bar{I}=0.20$. The glass-fiber/epoxy specimen experiences damage in $\sim 60 \%$ of the interlaminar "resin-rich" regions while the carbon-fiber/epoxy specimen experiences damage in $\sim 10 \%$ of the interlaminar regions. 

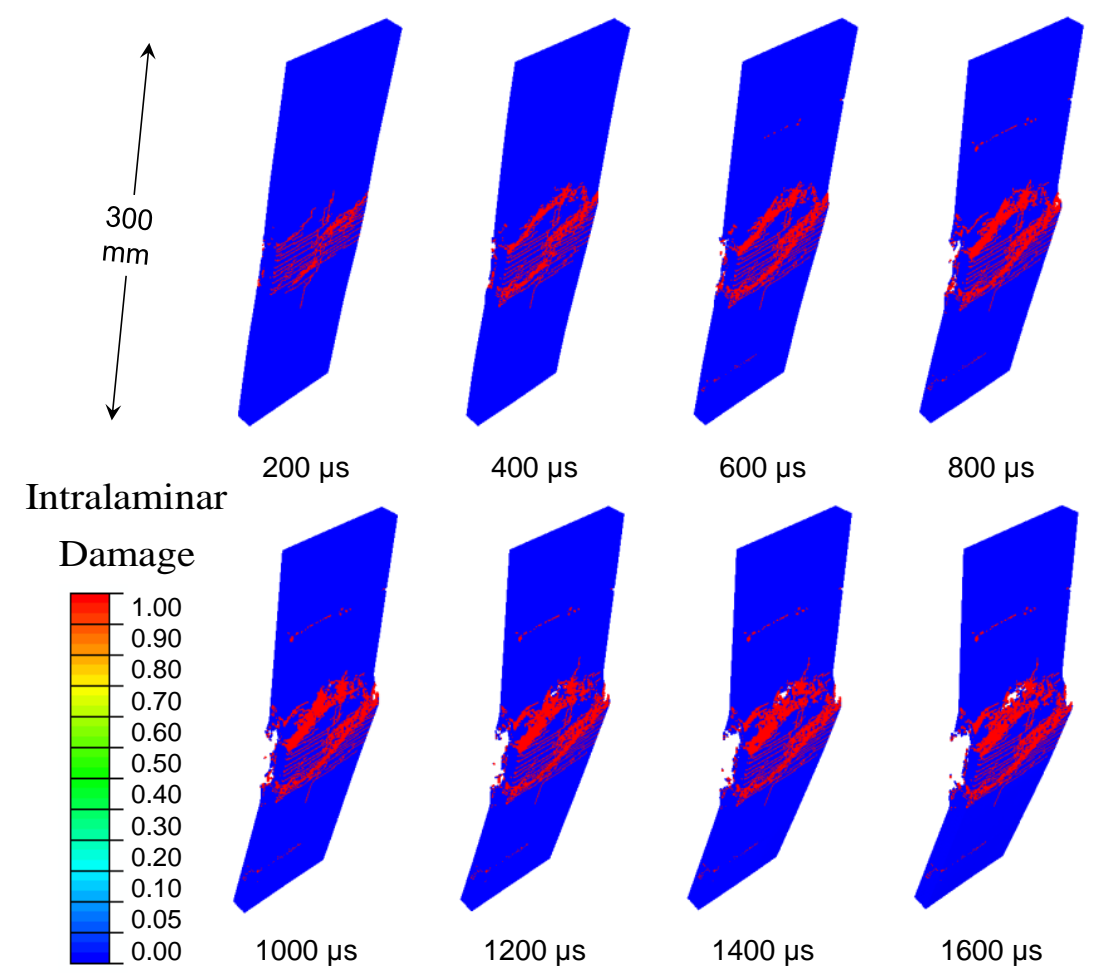

Figure 19 Distributions of in-ply damage in an obliquely loaded quasi-isotropic carbonfiber/epoxy composite laminate with $\theta=10^{\circ}$ subjected to $\bar{I}=0.20$.

\subsection{The effects of load obliquity on structural response}

The different angle of incidence creates complicated loading conditions with the bottom portion of the composite experiencing the incident impulse prior to the upper portion. The uneven incident loading leads to two different regions of highly localized damage. Distributions of damage in an obliquely loaded monolithic composite plate with $\theta=10^{\circ}$ subjected to $\bar{I}=0.20$ are shown in Figure 19. The higher angle of obliquity creates multiple locations of localized damage and causes rupture near the upper supports. A comparison of deformation in planarly loaded plates shown in Figure 9 and obliquely loaded plates in Figure 19 indicates that higher angles of obliquity increase the number of locations in which localized deformation takes place. 

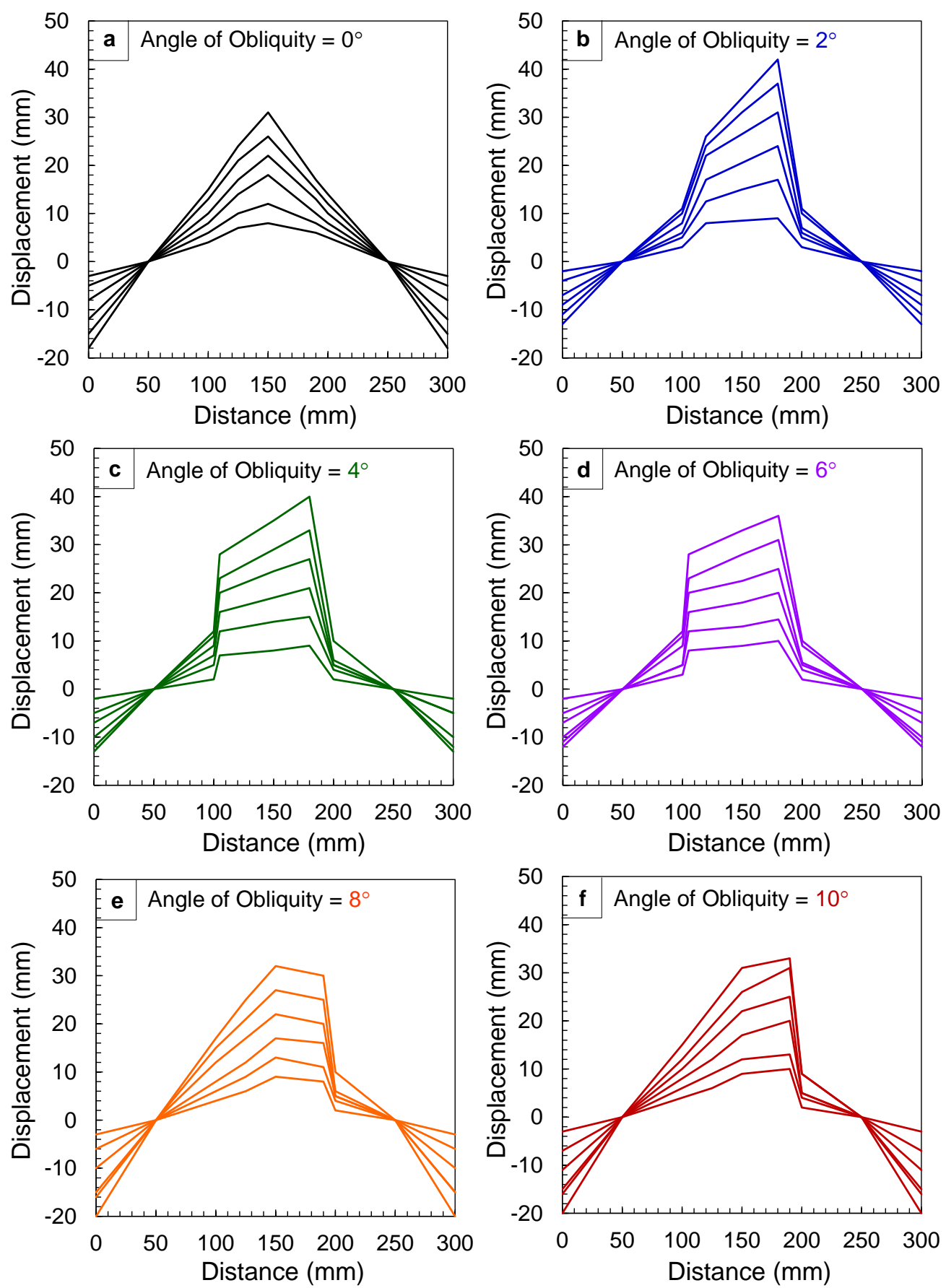

Figure 20 Out-of-plane displacement as a function of distance at $t=200,400,600,800$ and $1000 \mu \mathrm{s}$ for composite laminates with different angles of oblique loading subjected to similar underwater impulsive loads. 
Figure 20 shows the out-of-plane displacement as a function of distance along the impulsively loaded plates at $t=200,400,600,800$ and $1000 \mu \mathrm{s}$. A major aspect of deformation in a simply-supported bending configuration is the formation of a highly stressed region near the center of the plate which experiences the highest out-of-plane deflection. However, results indicate that increasing angle of obliquity causes localized deformation to be triggered in multiple locations of the plate. The severity of the damage depends on the magnitude of obliquity. Higher obliquity causes an incident wave with the same magnitude to interact with a smaller area leading causing rupture in a localized region which propagates through the rest of the plate. Figure 21 shows the intralaminar and interlaminar damage in quasi-isotropic carbonfiber/epoxy plates with different angles of obliquity subjected to $\bar{I}=0.20$. Both interlaminar and intralaminar damage increase with increasing angles of obliquity. There is $~ 5 \%$ increase in damage for every $2^{\circ}$ increase in the angle of obliquity.
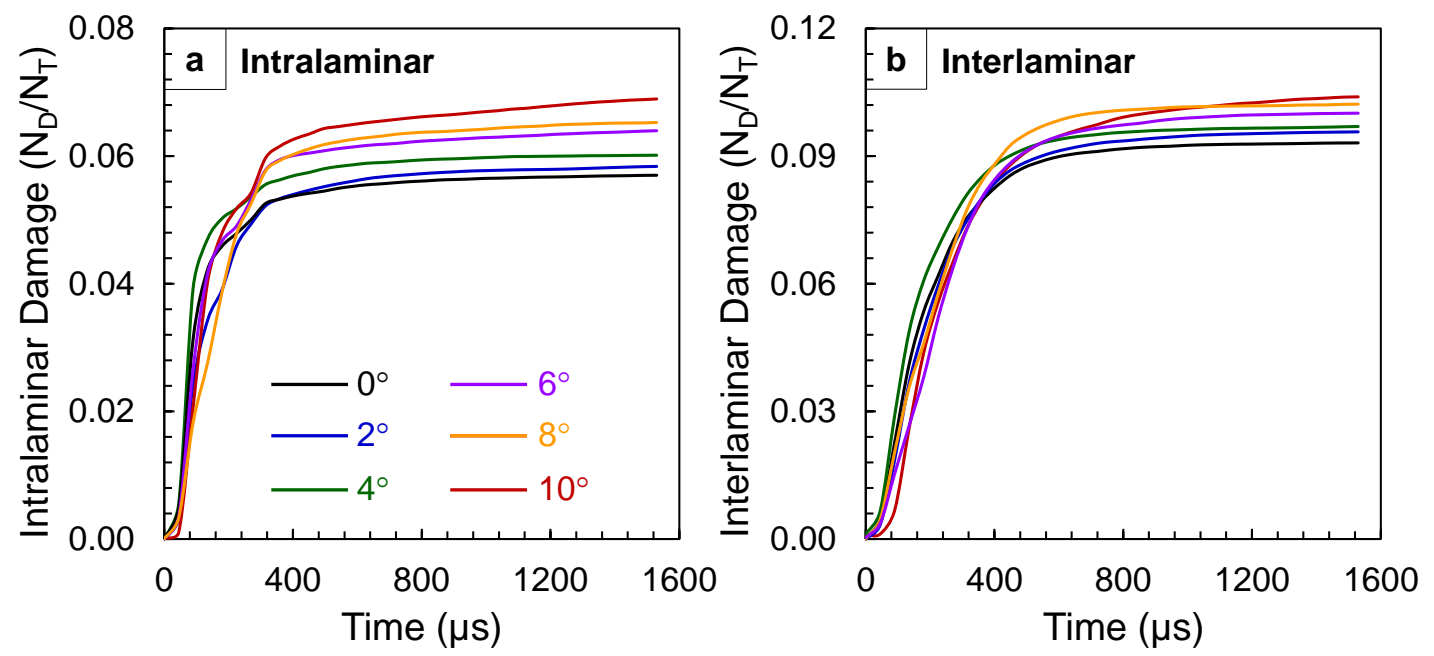

Figure 21 Calculated damage histories for carbon-fiber/epoxy and glass-fiber/epoxy laminates subjected to similar underwater impulsive loads. 


\section{Concluding remarks}

Marine structures must balance stiffness and load-carrying capacity with the ability to minimize impulse transmission for high blast and impact resistance. Composite structures have higher stiffness and strength-to-weight ratios compared to metallic structures. Additionally, thick composite laminates provide very high bending and shear resistances with relatively small increases in total mass. However, due to the novelty and wide range of structural combinations, the relationships between structural responses and material heterogeneity in composite structures are not well quantified. In particular, the behavior of composite structures under extreme impulsive loading generated by underwater explosions needs to be systematically analyzed. This research has been carried out to address this need.

The composite structures consist of both carbon-fiber and glass-fiber reinforced epoxy resin, and are manufactured by curing commercially available prepregs. The composites consist of $34 \%$ epoxy by weight, with the rest containing fibers. Four different composite layups are analyzed: (1) bi-axial; (2) quasi-isotropic; (3) unidirectional with fibers oriented parallel to supports; and (4) unidirectional with fibers oriented perpendicular to supports. It should be emphasized that the composite panels studied have quite similar in overall mass and thickness to enable comparison of performance. The combined experimental and computational research reported here focuses on the quantification of the water blast response of fiber-reinforced epoxy laminates with different material properties and stacking sequences under a range of incident impulsive loads. Since all plates experience failure under an incident impulse of $\bar{I}=0.16$ with a peak pressure of $196 \mathrm{MPa}$, this is the highest impulse intensity discussed in this paper. The experiments reported here are supported by a fully dynamic three-dimensional computational framework which employs a Coupled Eulerian Lagrangian (CEL) approach to capture the effects 
of underwater blasts and fluid-structure interactions (FSI). The results from numerical calculations provide a more in-depth understanding of temporal and spatial evolution of different deformation modes in the structures and the damage mechanisms in different components.

Comparison of experiments and simulations shows that numerical calculations provide a reasonable representation of damage and dissipation mechanisms in the composite laminates. The finite element model captures the essential deformation mechanisms observed in both carbon-fiber and glass-fiber/epoxy laminates. Specifically, the following are replicated with reasonable accuracy: fluid-structure interaction effects at the water-structure interface, effects of fiber orientation, in-ply matrix and fiber cracking and rupture, and inter-ply delamination initiation and evolution. The Hashin damage model overestimates the softening effect resulting from cracking and fracture leading to a slight underestimation of backface deflection.

The unidirectional layups experience splitting due to a lack of stability in the transverse direction, while the bi-axial layups undergo failure near the loading circumference in close proximity to the impulsively loaded region. Quasi-isotropic layups provide the highest blast resistance for both the carbon-fiber and glass-fiber epoxy laminates. Additionally, the quasiisotropic carbon-fiber/epoxy laminates experience $70 \%$ of the deflection experienced by glassfiber/epoxy laminates. Since carbon-fiber laminates are nearly four times stiffer than glass-fiber laminates, it is expected that these laminates will transfer higher impulses due to more efficient load spreading. The impulse transmitted by the carbon-fiber laminates is $\sim 130 \%$ of that transmitted by glass-fiber laminates, which is relatively modest increase in comparison to superior deflection resistance and reduced in-ply as well as inter-ply damage. In terms of accumulated damage, the carbon-fiber laminates experience $25 \%$ of the damage experience by glass-fiber laminates. 
To evaluate the effects of load obliquity on the dynamic response of composite laminates, the loading angle is varied from $0^{\circ}$ to $10^{\circ}$ with increments of $2^{\circ}$ and each loading configuration is subjected to similar incident loads. Results indicate that increasing angle of obliquity causes localized deformation to be triggered in multiple locations of the plate. Intralaminar damage increases with increasing angles of obliquity, while interlaminar damage is relatively insensitive to load obliquity. There is an $\sim 5 \%$ increase in intralaminar damage for every $2^{\circ}$ increase in the angle of obliquity.

\section{Acknowledgement}

The authors gratefully acknowledge support by the Office of Naval Research through grant numbers N00014-09-1-0808 and N00014-09-1-0618 (program manager: Dr. Yapa D. S. Rajapakse). Calculations were carried out on computers in the DOD High Performance Computing Modernization Program (HPCMP) and on the Athena HPC cluster in the Dynamic Properties Research Laboratory (DPRL) at Georgia Tech. MZ also acknowledges beneficial interactions through the CAS/SAFEA International Partnership Program for Creative Research Teams.

\section{References}

[1] F.K. Chang, H.Y. Choi, S.T. Jeng, Study on Impact Damage in Laminated Composites, Mech Mater, 10 (1990) 83-95.

[2] F.K. Chang, H.Y. Choi, S.T. Jeng, Characterization of Impact Damage in Laminated Composites, Sampe J, 26 (1990) 18-25.

[3] L.B. Lessard, F.K. Chang, Damage Tolerance of Laminated Composites Containing an Open Hole and Subjected to Compressive Loadings .2. Experiment, J Compos Mater, 25 (1991) 44-64. [4] W.J. Cantwell, J. Morton, The Impact Resistance of Composite-Materials - a Review, Composites, 22 (1991) 347-362.

[5] Z. Hashin, Analysis of Stiffness Reduction of Cracked Cross-Ply Laminates, Eng Fract Mech, 25 (1986) 771-778.

[6] Z. Hashin, Analysis of Orthogonally Cracked Laminates under Tension, J Appl Mech-T Asme, 54 (1987) 872-879. 
[7] K. Minnaar, M. Zhou, A novel technique for time-resolved detection and tracking of interfacial and matrix fracture in layered materials, Journal of the Mechanics and Physics of Solids, 52 (2004) 2771-2799.

[8] H.D. Espinosa, S. Lee, N. Moldovan, A novel fluid structure interaction experiment to investigate deformation of structural elements subjected to impulsive loading, Experimental Mechanics, 46 (2006) 805-824.

[9] F. Latourte, D. Gregoire, D. Zenkert, X.D. Wei, H.D. Espinosa, Failure mechanisms in composite panels subjected to underwater impulsive loads, Journal of the Mechanics and Physics of Solids, 59 (2011) 1623-1646.

[10] X.D. Wei, A. de Vaucorbeil, P. Tran, H.D. Espinosa, A new rate-dependent unidirectional composite model - Application to panels subjected to underwater blast, Journal of the Mechanics and Physics of Solids, 61 (2013) 1305-1318.

[11] M. Battley, T. Allen, Servo-hydraulic System for Controlled Velocity Water Impact of Marine Sandwich Panels, Experimental Mechanics, 52 (2012) 95-106.

[12] M. Battley, I. Stenius, J. Breder, S. Edinger, Dynamic characterisation of marine sandwich structures, Sandwich Structures7: Advancing with Sandwich Structures and Materials, (2005) 537-546.

[13] S.A. Tekalur, A.E. Bogdanovich, A. Shukla, Shock loading response of sandwich panels with 3-D woven E-glass composite skins and stitched foam core, Composites Science and Technology, 69 (2009) 736-753.

[14] S.A. Tekalur, A. Shukla, K. Shivakumar, Blast resistance of polyurea based layered composite materials, Composite Structures, 84 (2008) 271-281.

[15] J. LeBlanc, A. Shukla, C. Rousseau, A. Bogdanovich, Shock loading of three-dimensional woven composite materials, Composite Structures, 79 (2007) 344-355.

[16] J. Grogan, S.A. Tekalur, A. Shukla, A. Bogdanovich, R.A. Coffelt, Ballistic resistance of 2D and 3D woven sandwich composites, Journal of Sandwich Structures \& Materials, 9 (2007) 283-302.

[17] E.H. Wang, N. Gardner, A. Shukla, The blast resistance of sandwich composites with stepwise graded cores, International Journal of Solids and Structures, 46 (2009) 3492-3502.

[18] S. Avachat, M. Zhou, High-speed digital imaging and computational modeling of dynamic failure in composite structures subjected to underwater impulsive loads, International Journal of Impact Engineering, 77 (2015) 147-165.

[19] A. Schiffer, V.L. Tagarielli, The one-dimensional response of a water-filled double hull to underwater blast: Experiments and simulations, International Journal of Impact Engineering, 63 (2014) 177-187.

[20] A. Schiffer, V.L. Tagarielli, The response of rigid plates to blast in deep water: fluidstructure interaction experiments, Proceedings of the Royal Society a-Mathematical Physical and Engineering Sciences, 468 (2012) 2807-2828.

[21] S. Avachat, M. Zhou, Effect of Facesheet Thickness on Dynamic Response of Composite Sandwich Plates to Underwater Impulsive Loading, Experimental Mechanics, Volume 52 (2011) pp 83-93.

[22] S. Avachat, M. Zhou, Dynamic Response Of Composite Sandwich Structures Subjected To Underwater Impulsive Loads: Experiments And Simulations Conference Proceedings of the 16th International Conference on Composite Structures, ICCS-16, A. J. M. Ferreira (Editor), FEUP, Porto, 2011, (2011). 
[23] S. Avachat, M. Zhou, Dynamic Response of Submerged Composite Sandwich Structures to Blast Loading, Proceedings of the IMPLAST 2010 - SEM Fall Conference, October 12-14 2010 Providence, Rhode Island, USA, Arun Shukla (Editor), (2010).

[24] X.D. Wei, P. Tran, A. de Vaucorbeil, R.B. Ramaswamy, F. Latourte, H.D. Espinosa, Threedimensional numerical modeling of composite panels subjected to underwater blast, Journal of the Mechanics and Physics of Solids, 61 (2013) 1319-1336.

[25] M.M. Swisdak, Explosion effects and properties: Part II - explosion effects in water, Technical Report, Naval Surface Weapons Center, Dahlgren, Virginia, USA, (1978).

[26] G.I. Taylor, The pressure and impulse of submarine explosion waves on plates. , The scientific papers of G I Taylor, vol. III, pp. 287-303. Cambridge: Cambridge University Press, (1941).

[27] H. Arora, M. Kelly, A. Worley, P. Del Linz, A. Fergusson, P.A. Hooper, J.P. Dear, Compressive strength after blast of sandwich composite materials, Philosophical Transactions of the Royal Society a-Mathematical Physical and Engineering Sciences, 372 (2014).

[28] H. Arora, P.A. Hooper, J.P. Dear, The Effects of Air and Underwater Blast on Composite Sandwich Panels and Tubular Laminate Structures, Experimental Mechanics, 52 (2012) 59-81.

[29] G.I. Taylor, The Scientific Papers of G I Taylor, Cambridge University Press, Cambridge, (1963).

[30] N. Kambouchev, R. Radovitzky, L. Noels, Fluid-structure interaction effects in the dynamic response of free-standing plates to uniform shock loading, Journal of Applied MechanicsTransactions of the Asme, 74 (2007) 1042-1045.

[31] J.W. Hutchinson, Energy and Momentum Transfer in Air Shocks, Journal of Applied Mechanics-Transactions of the Asme, 76 (2009).

[32] Z. Hashin, Failure Criteria for Unidirectional Fiber Composites, J Appl Mech-T Asme, 47 (1980) 329-334.

[33] A. Puck, H. Schürmann, Failure analysis of FRP laminates by means of physically based phenomenological models, Composites Science and Technology, Volume 62, Issues 12-13, September-October 2002, Pages 1633-1662, (1999).

[34] P.M. Schubel, J.J. Luo, I.M. Daniel, Low velocity impact behavior of composite sandwich panels, Composites Part a-Applied Science and Manufacturing, 36 (2005) 1389-1396.

[35] A.H. Kiel, The Response of Ships to Underwater Explosions, Department of the Navy, (1961).

[36] S. Chan, Z. Fawaz, K. Behdinan, R. Amid, Ballistic limit prediction using a numerical model with progressive damage capability, Composite Structures, 77 (2007) 466-474.

[37] S.T. Pinho, P. Robinson, L. Iannucci, Fracture toughness of the tensile and compressive fibre failure modes in laminated composites, Composites Science and Technology, 66 (2006) 2069-2079.

[38] I. Lapczyk, J.A. Hurtado, Progressive damage modeling in fiber-reinforced materials, Composites Part a-Applied Science and Manufacturing, 38 (2007) 2333-2341.

[39] A. Needleman, An analysis of tensile decohesion along an interface, J. Mech. Phys. Solids, 38 (1990) 289-324.

[40] V. Tvergaard, J.W. Hutchinson, The Relation between Crack-Growth Resistance and Fracture Process Parameters in Elastic Plastic Solids, Journal of the Mechanics and Physics of Solids, 40 (1992) 1377-1397. 
[41] V. Tvergaard, A. Needleman, Effect of Crack Meandering on Dynamic, Ductile Fracture, Journal of the Mechanics and Physics of Solids, 40 (1992) 447-471.

[42] A. Needleman, V. Tvergaard, Mesh Effects in the Analysis of Dynamic Ductile CrackGrowth, Engineering Fracture Mechanics, 47 (1994) 75-91.

[43] X.P. Xu, A. Needleman, Numerical Simulations of Fast Crack-Growth in Brittle Solids, Journal of the Mechanics and Physics of Solids, 42 (1994) 1397-\&.

[44] G.T. Camacho, M. Ortiz, Computational modelling of impact damage in brittle materials, International Journal of Solids and Structures, 33 (1996) 2899-2938.

[45] H.D. Espinosa, P.D. Zavattieri, S.K. Dwivedi, A finite deformation continuum discrete model for the description of fragmentation and damage in brittle materials, in, PergamonElsevier Science Ltd, 1998, pp. 1909-1942.

[46] P.P. Camanho, C.G. Davila, M.F. de Moura, Numerical simulation of mixed-mode progressive delamination in composite materials, Journal of Composite Materials, 37 (2003) $1415-1438$.

[47] K. Minnaar, M. Zhou, Characterization of impact in composite laminates, AIP Conference Proceedings, 620 (2002) 1208.

[48] J. Zhai, M. Zhou, Finite element analysis of micromechanical failure modes in a heterogeneous ceramic material system, International Journal of Fracture, 101 (2000) 161-180.

[49] A.S. Gullerud, X.S. Gao, R.H. Dodds, R. Haj-Ali, Simulation of ductile crack growth using computational cells: numerical aspects, Engineering Fracture Mechanics, 66 (2000) 65-92.

[50] V. Tomar, J. Zhai, M. Zhou, Bounds for element size in a variable stiffness cohesive finite element model, International Journal for Numerical Methods in Engineering, 61 (2004) 18941920. 